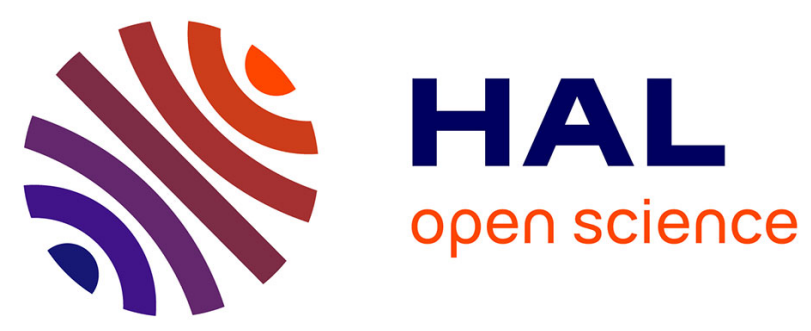

\title{
Determination of surface amine groups on amorphous carbon nitride thin films using a one step covalent grafting of a redox probe
}

Samar Jribi, Suzanna I. Cordoba de Torresi, T Augusto, Hubert Cachet, Catherine Debiemme-Chouvy, Claude Deslouis, Alain Pailleret

\section{To cite this version:}

Samar Jribi, Suzanna I. Cordoba de Torresi, T Augusto, Hubert Cachet, Catherine DebiemmeChouvy, et al.. Determination of surface amine groups on amorphous carbon nitride thin films using a one step covalent grafting of a redox probe. Electrochimica Acta, 2014, 136, pp.473 - 482. 10.1016/j.electacta.2014.05.042 . hal-01079209

\section{HAL Id: hal-01079209 https://hal.science/hal-01079209}

Submitted on 4 Nov 2014

HAL is a multi-disciplinary open access archive for the deposit and dissemination of scientific research documents, whether they are published or not. The documents may come from teaching and research institutions in France or abroad, or from public or private research centers.
L'archive ouverte pluridisciplinaire HAL, est destinée au dépôt et à la diffusion de documents scientifiques de niveau recherche, publiés ou non, émanant des établissements d'enseignement et de recherche français ou étrangers, des laboratoires publics ou privés. 


\title{
Determination of surface amine groups on amorphous carbon nitride thin films using a one step covalent grafting of a redox probe
}

\author{
S. Jribi ${ }^{1,2}$, S.I. Cordoba de Torresi ${ }^{3}$, T. Augusto $^{3}$, H. Cachet ${ }^{1,2}$, C. Debiemme-Chouvy ${ }^{1,2}$, \\ C. Deslouis ${ }^{1,2}$, A. Pailleret $^{1,2}$ \\ ${ }^{1}$ Sorbonne Universités, UPMC Univ. Paris VI, UMR 8235, Labo. Interfaces et Systèmes \\ Electrochimiques (LISE), 4, place Jussieu, case courrier 133, F-75005, Paris, France \\ ${ }^{2-}$ CNRS, UMR 8235, LISE, F-75005, Paris, France \\ ${ }^{3}$ Instituto de Química, Universidade de São Paulo, C.P. 26077, 05513-970, Sao Paulo(SP) \\ Brasil
}

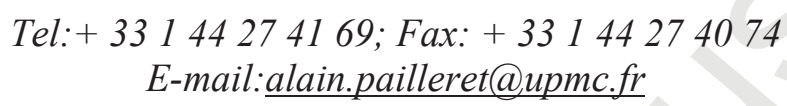

\begin{abstract}
A fluorocarbonyl terminated ferrocene based redox probe was synthesized and characterized using infrared spectroscopy and nuclear magnetic resonance. It was then successfully grafted on various amorphous carbon nitride $\left(\mathrm{a}-\mathrm{CN}_{\mathrm{x}}\right)$ samples $(0.12 \leq \mathrm{x} \leq 0.27)$ via the formation of a -CO-NH- type linkage with surface amine groups, whose spontaneous formation on the surface of a- $\mathrm{CN}_{\mathrm{x}}$ materials was thus proved and exploited. Cyclic voltammetry experiments were carried out in an acidic aqueous solution in the presence of this freely diffusing redox probe, in order to identify its electrochemical behavior. By comparison, $\mathrm{CV}$ experiments carried out on the modified a- $\mathrm{CN}_{\mathrm{x}}$ electrodes in the same blank electrolytic solution undoubtedly confirmed the presence of electroactive sub-monolayers, in spite of distortions of the resulting voltammograms. These latter were shown to reflect the influence of bulk atomic nitrogen content on the electrochemical reactivity of a-CN $\mathrm{CN}_{\mathrm{x}}$ materials. The grafted surface amine percentage deduced from the charge passed during oxidation of grafted ferrocene moieties was found to decrease from $6.5 \%$ for a- $\mathrm{CN}_{0.12}$ down to $1.1 \%$ for a- $\mathrm{CN}_{0.27}$. This trend is expected to reflect the trend in surface concentration of reactive amine groups as a function of bulk atomic nitrogen content.
\end{abstract}




\section{Introduction}

Over the last few years and until now, carbon materials were the target of an intense and growing research activity. A major contribution to this latter is aimed at exploiting their surface as a starting platform for various molecular architectures in view of various applications such as electrochemical or bio-sensors, molecular electronics or coatings with special physical or chemical properties [1-3]. As an example and besides glassy carbon or raw carbon materials (such as graphite), thin films of boron doped diamond (BDD) have been widely investigated in this research field due to their remarkable physical properties: mechanical resistance, chemical stability, biocompatibility and electronic conductivity [4]. In electrochemistry, these materials show weak parasitic current densities and wide potential windows in aqueous media. On the other hand, their surface functionalisation requires an appropriate pre-treatment depending on the initially existing surface functional groups of the as-grown materials produced from the plasma based deposition process. These functional groups may also result from the reactivity in the presence of atmospheric water and oxygen.

Though sustained activity was long-carried out on the investigation of electronic, structural or mechanical properties of amorphous carbon or carbon nitride materials [5-7], much less effort, and only since the end of the nineties, was put on their use as electrode materials: however both $a-\mathrm{CN}_{\mathrm{x}}$ or $\mathrm{a}-\mathrm{CN}_{\mathrm{x}} \mathrm{H}_{\mathrm{y}}$ were purposely envisaged and their electrochemical activity assessed with respect to different redox couples [8-19].

a- $\mathrm{CN}_{\mathrm{x}}$ materials have been suggested for applications in liquid effluent treatment (nitrate reduction on the cathodic side, degradative oxidation of organic pollutants on the anodic side) but no achievement emerged so far. Conversely, applications in electroanalysis for heavy metals detection by stripping voltammetry [20-23] or biological analyte detection [24], in catalysis [25,26], for anti-corrosion coatings [27-29], humidity sensing [30], elaboration of a-CN $\mathrm{CN}_{\mathrm{x}}$ (or a-C)/metal composite materials [31-32] or new p-n junctions [33-34] 
have been proposed. Moreover, these materials possess a very smooth surface, as shown from AFM images on a-CN $\mathrm{CN}_{\mathrm{x}}$ films when deposited by cathodic sputtering on doped silicon [35].

A development of a-CN $\mathrm{CN}_{\mathrm{x}}$ based biosensors following the examples of graphite or BDD requires first to determine the amine surface groups naturally expected for this material at variance with the former two ones. The next question to come: is a further amination necessary? There is an abundant literature dealing with the characterization of chemical composition and $\mathrm{C} / \mathrm{N}$ bond structures in a- $\mathrm{CN}_{\mathrm{x}}$ or a- $\mathrm{CN}_{\mathrm{x}} \mathrm{H}_{\mathrm{y}}$ materials depending upon the nature of precursors, $\mathrm{N}_{2}$ partial pressure in the sputtering gas, or power imposed during the deposition process. Either vibrational (IR or Raman) spectroscopies or XPS technique allowed to prove the existence of $\mathrm{sp}^{3}$ to $\mathrm{sp}^{1}(\mathrm{C}-\mathrm{N}, \mathrm{C}=\mathrm{N}$ or $\mathrm{C} \equiv \mathrm{N})$ hybridizations $[6,13,16,36$ 42]. In particular, infrared absorption spectra of a-CN $\mathrm{CN}_{\mathrm{x}}$ thin films showed bands at $1220 \mathrm{~cm}^{-1}$ and $1650 \mathrm{~cm}^{-1}$ that can be reasonably assigned to $\mathrm{sp}^{3} \mathrm{C}-\mathrm{N}$ and $\mathrm{sp}^{2} \mathrm{C}=\mathrm{N}$ bonds respectively $[6,13,43]$. In addition, FTIR spectra of a- $\mathrm{CN}_{\mathrm{x}}$ thin films were shown to exhibit a very high visible to infrared transmittance and to reveal surface amine groups $\left(-\mathrm{NH}_{2}\right)$ [44]. All these indications lead to the conclusion that the spontaneous formation of amine- and imine-type functional groups on a-CN $\mathrm{CN}_{\mathrm{x}}$ materials is more than likely, as a result of the reactivity of a- $\mathrm{CN}_{\mathrm{x}}$ materials towards atmospheric water and oxygen as soon as they are withdrawn from the deposition chamber [45]. Nevertheless, surface amine groups have never been exploited for the development of covalent grafting strategies on a-CN $\mathrm{N}_{\mathrm{x}}$ surfaces in literature.

Surface IR or FTIR spectroscopies do not provide a quantitative determination of the different $\mathrm{C}-\mathrm{N}$ bonds coverage, and surface Raman on glassy carbon gives, even with a sophisticated treatment, overestimates of the coverage by an organic monolayer as compared to cyclic voltammetry $(\mathrm{CV})$ [46]. In the case of a- $\mathrm{CN}_{\mathrm{x}}$ materials, XPS is not appropriate to this end since the probed thickness of the material is about $10 \mathrm{~nm}$, which brings a significant contribution of bulk nitrogen atoms with respect to the surface ones. The EDC/NHS technique 
[47] allows grafting of carboxyl-substituted redox compounds to amine surface groups for further electrochemical signature and evaluation of amine sites. As this technique, widely recognized, is specific of primary amines, we propose in this work an alternative grafting route. More precisely, the one-step grafting of a well-known reversible redox probe, i.e. a ferrocene moiety, is reported, probably for the first time on a- $\mathrm{CN}_{\mathrm{x}}$ thin films, via the formation of an amide bond between the a- $\mathrm{CN}_{\mathrm{x}}$ surfaces and the redox probe. It therefore confirms the reasonable abovementioned expectations predicting the presence of amine functional groups on the surface. In addition, cyclic voltammetry experiments carried out on the grafted surfaces allowed an approach of the determination of the number of amine groups per surface unit assumed uniformly distributed, for $\mathrm{a}-\mathrm{CN}_{\mathrm{x}}$ samples with different atomic nitrogen contents.

\section{Experimental}

\subsection{Preparation of a-CN $\mathrm{CN}_{\mathrm{x}}$ samples}

a-CN $\mathrm{C}_{\mathrm{x}}$ thin films were deposited on boron doped (p-type) silicon substrates (doping level: $10^{20} \mathrm{~cm}^{-3}$, resistivity: $1-5 \mathrm{~m} \Omega . \mathrm{cm}$ ) with the help of DC magnetron cathodic sputtering technique using a graphite target and a reactive $\mathrm{Ar} / \mathrm{N}_{2}$ plasma. The reactor used was a MP 300 S model from Plassys (France). The substrates were first sonicated in successive distilled water, acetone and ethanol baths, then allowed to dry in air, and finally submitted to an RF (13.56 MHz) ionic etching (substrate + target) in the reactor. The films were produced using a 0.4 $\mathrm{Pa}$ total pressure, a 10 min deposition time and a $250 \mathrm{~W}$ target power for various gaseous nitrogen contents $(3,7,15$ and $30 \%)$ in the sputtering gas mixture. The target-to-substrate distance was $c a .7 \mathrm{~cm}$. 


\subsection{Chemical synthesis of the grafted redox-active molecules}

The ferrocene based redox probes intended for grafting experiments were prepared according to the synthetic route shown in Scheme 1 and resulting from a modified procedure reported in literature $[48,49]$.

\subsubsection{Synthesis of compound $\underline{\mathbf{2}}$}

Ferrocenecarboxylic acid ( $2 \mathrm{mmol}$, compound $\underline{\mathbf{1}}$ ) was dissolved in dichloromethane $(25 \mathrm{~mL})$ and then stirred under argon atmosphere in an ice bath $\left(0^{\circ} \mathrm{C}\right)$ for 10 minutes. Pyridine (4 mmol) and cyanuric fluoride (4 mmol) were added in the solution and the argon flux was stopped and the resulting mixture contained in a closed glass vessel was kept under stirring for 2 hours. Ice cubes made from distilled water were then added to the mixture placed under stirring. The filtered solution resulted at rest in two immiscible phases. After separation, the orange-brown organic phase was washed twice using frozen water. The washed organic phase was then dried with the help of magnesium sulphate, carefully filtered and washed again using dichloromethane. The resulting solution was stored under vacuum until the solvent was completely evaporated, producing then a dark orange powder that was purified by recrystallisation using hexane first and then dichloromethane so as to obtain an orange powder. It was characterized using ${ }^{1} \mathrm{H}$ NMR $\left(300 \mathrm{MHz}\right.$ in $\mathrm{CDCl}_{3}$ ) and ${ }^{13} \mathrm{C} \mathrm{NMR}(75 \mathrm{MHz}$ in DMSO$\mathrm{d}_{6}$ ) as well as IR spectroscopy in a $\mathrm{KBr}$ pellet loaded with the reaction product. Identification of the peaks confirmed the production of fluorocarbonylferrocene $\underline{2} \cdot{ }^{1} \mathrm{H}$ NMR $\delta(\mathrm{ppm}): 4.37$ $\left(\mathrm{s}, 5 \mathrm{H}, \mathrm{C}_{5} \mathrm{H}_{5}\right), 4.75\left(\mathrm{~d}, 2 \mathrm{H},{ }^{1} \mathrm{~J}=1.6 \mathrm{~Hz}, \mathrm{C}_{5} \mathrm{H}_{4}\right), 4.91\left(\mathrm{t}, 2 \mathrm{H},{ }^{1} \mathrm{~J}=1.6 \mathrm{~Hz}, \mathrm{C}_{5} \mathrm{H}_{4}\right) .{ }^{13} \mathrm{C} \mathrm{NMR}$ $\delta(\mathrm{ppm}): 164.3(\mathrm{C}=\mathrm{O}), 73.3\left(\mathrm{C}_{5} \mathrm{H}_{4}\right), 70.6\left(\mathrm{C}_{5} \mathrm{H}_{4}\right), 69.9\left(\mathrm{C}_{5} \mathrm{H}_{5}\right) . \mathrm{IR} v\left(\mathrm{~cm}^{-1}\right): 3092 v(\mathrm{CH}), 1801$ $v(\mathrm{C}=\mathrm{O}), 1474 v(\mathrm{CC}), 1373 v(\mathrm{CF}), 1271 v(\mathrm{CO}), 1072 \delta(\mathrm{CH}), 1107 \delta(\mathrm{CH}), 895 \pi(\mathrm{CH}), 756$ $\pi(\mathrm{CH}), 698 \pi(\mathrm{CH}), 480 v(\mathrm{Fe}-\mathrm{Cp})$.

\subsubsection{Synthesis of compound $\underline{3}$}


Compound $\underline{\mathbf{2}}(2 \mathrm{mmol})$ was dissolved in anhydrous tetrahydrofurane (THF) under constant argon atmosphere to avoid fluorhydric acid formation. $\beta$-alanine $(2.33 \mathrm{mmol})$ was added and the reaction mixture was stirred for five days under argon bubbling at ambient temperature. After reactants in excess have been removed by washing, the solvent was removed under vacuum and the remaining powder was re-crystallised using hexane first and then dichloromethane so as to obtain an orange powder. The addition of the $\beta$-alanine moiety on fluorocarbonylferrocene $\underline{\mathbf{2}}$ via formation of an amide type linkage and the subsequent synthesis of compound $\underline{\mathbf{3}}$ were confirmed: ${ }^{1} \mathrm{H}$ NMR $\delta(\mathrm{ppm}): 4.20\left(\mathrm{~s}, 2 \mathrm{H}, \mathrm{C}_{5} H_{5}\right), 4.33(\mathrm{t}, 2 \mathrm{H}$, $\left.\mathrm{C}_{5} \mathrm{H}_{4}\right), 4.65\left(\mathrm{t}, \mathrm{C}_{5} \mathrm{H}_{4}\right), 3.36\left(\mathrm{dt}, 2 \mathrm{H}, \mathrm{CH}_{2} \mathrm{NH}\right), 2.35\left(\mathrm{t}, 2 \mathrm{H}, \mathrm{CH}_{2} \mathrm{COOH}\right) ;{ }^{13} \mathrm{C} \mathrm{NMR} \delta(\mathrm{ppm})$ : $175.37(\mathrm{COOH}), \quad 169.46(\mathrm{CONH}), \quad 70.11\left(C_{5} \mathrm{H}_{5}\right), \quad 68.96, \quad 70.61,77.68\left(C_{5} \mathrm{H}_{4}\right), 34.52$ $\left(\mathrm{CH}_{2} \mathrm{COOH}\right)$.

\subsubsection{Synthesis of compound $\underline{4}$}

Compound $\underline{\mathbf{4}}$ was obtained after compound $\underline{\mathbf{3}}$ had undergone the synthetic route applied on ferrocenecarboxylic acid to get fluorocarbonylferrocene $\underline{\mathbf{2}}$, as the purpose of this last step is again to make the fluorinated compound from the carboxylic acid compound. Briefly, a suspension of $0.67 \mathrm{~g}$ of compound $\underline{\mathbf{3}}(2 \mathrm{mmol})$ and pyridine $(4 \mathrm{mmol})$ in dry dichloromethane $(60 \mathrm{~mL})$ was cooled to $0^{\circ} \mathrm{C}$ under argon atmosphere. To this solution cyanuric fluoride $(10 \mathrm{mmol})$ was added and the mixture stirred for $3 \mathrm{~h}$. A copper color was observed. Crushed ice/water (50 g) was then added, the suspension filtered, and the organic layer separated and washed with cold water. The organic layer was then dried over anhydrous $\mathrm{MgSO}_{4}$ and filtered. Solvent removal was performed under vacuum and a dark crystalline orange solid was obtained.

The production of compound $\underline{4}$ was confirmed: ${ }^{1} \mathrm{H}$ NMR $\delta(\mathrm{ppm}): 4.65\left(\mathrm{t}, 2 \mathrm{H}, \mathrm{C}_{5} H_{4}\right)$, $4.33\left(\mathrm{t}, 2 \mathrm{H}, \mathrm{C}_{5} \mathrm{H}_{4}\right), 4.19\left(\mathrm{~s}, 5 \mathrm{H}, \mathrm{C}_{5} \mathrm{H}_{5}\right), 3.36\left(\mathrm{dt}, 2 \mathrm{H}, \mathrm{CH}_{2} \mathrm{NH}\right), 2,49\left(\mathrm{t}, 2 \mathrm{H}, \mathrm{CH}_{2} \mathrm{COF}\right) ;{ }^{13} \mathrm{C}$ NMR $\delta(p p m): 164(C O F), 169.46(C O N H), 70.1\left(C_{5} \mathrm{H}_{5}\right), 68.96,70.61,77.84\left(C_{5} \mathrm{H}_{4}\right), 32.19$ 
$\left(\mathrm{CH}_{2} \mathrm{COF}\right) . \mathrm{IR} v\left(\mathrm{~cm}^{-1}\right): 3368 v(\mathrm{NH}),\left(3097 v(\mathrm{CH}), 2962 v\left(\mathrm{CH}_{2}\right), v(\mathrm{C}=\mathrm{O}), 1474 v(\mathrm{CC}), 1383\right.$ $v(\mathrm{CF}), 1271 v(\mathrm{CO}), 1072 \delta(\mathrm{CH}), 1107 \delta(\mathrm{CH}), 895 \pi(\mathrm{CH}), 756 \pi(\mathrm{CH}), 698 \pi(\mathrm{CH}), 482 v(\mathrm{Fe}-$ $\mathrm{Cp})$.

\subsection{XPS measurements}

The XPS analyses were performed on a VG ESCALAB 250-i XL spectrometer using a monochromatic $\mathrm{Al} \mathrm{K}_{\alpha} \mathrm{X}$-ray source. The survey and the high-resolution spectra were recorded at a pass energy of 150 and $20 \mathrm{eV}$, respectively. However for $\mathrm{Fe}$ and $\mathrm{F}$ detection, the pass energy was fixed at $75 \mathrm{eV}$. The photoelectron take-off angle was $90^{\circ}$ with respect to the a- $\mathrm{CN}_{\mathrm{x}}$ surface. The background was removed using the Shirley's method. All the binding energy (BE) scales were referenced by setting the $\mathrm{C} 1 \mathrm{~s}$ main contribution $\mathrm{BE}$ to $285 \mathrm{eV}$.

\subsection{SEM-FEG and AFM experiments}

The thickness measurements of a- $\mathrm{CN}_{\mathrm{x}}$ films were carried out using a FEG-SEM (ULTRA 55 FEG-SEM from CARL ZEISS SMT). a-CN $\mathrm{N}_{\mathrm{x}}$ sample cross-sections were exposed by separating them in two pieces with the help of a diamond tip. AFM observations were carried out in air using a Molecular Imaging instrument in the contact mode. For this purpose, silicon nitride triangular cantilevers bearing pyramidal silicon nitride tips and possessing a $0.38 \mathrm{~N} . \mathrm{m}^{-}$

${ }^{1}$ spring constant were used. The scan rate used for all experiments was $8000 \mathrm{~nm} \cdot \mathrm{s}^{-1}$. The AFM image shown hereafter underwent a plane correction process produced with the help of the Picoscan software. This latter as well as a home-made software were used to determine respectively RMS roughness values and real surface areas, all reported later on in this manuscript for the full area of $2 \times 2 \mu \mathrm{m}^{2}$ AFM images.

\subsection{Grafting method and electrochemical tests}


For the need of grafting and electrochemical tests, glass substrates $(1 \mathrm{~cm} \times 7 \mathrm{~cm})$ were covered on one side with a sticky copper tape. The boron doped silicon substrates bearing the a- $\mathrm{CN}_{\mathrm{x}}$ thin films were first scratched on the backside using a cutter and then stuck on the copper tape using a few drops of InGa liquid alloy for making an ohmic contact. The copper tape and the edges of the a- $\mathrm{CN}_{\mathrm{x}}$ film were then insulated with epoxy glue leaving bare the other extremity of the copper tape so as to allow for the electrical contact towards the potentiostat inputs. The exposed a- $\mathrm{CN}_{\mathrm{x}}$ geometric area value (see $\mathrm{S}$ values in Table 1) was determined for each electrode by using a digital image processing from pictures of the electrode surface.

The grafting procedure consisted in dipping the a- $\mathrm{CN}_{\mathrm{x}}$ electrodes in a $0.01 \mathrm{M}$ solution of the soluble redox probe $\underline{4}$ in dry tetrahydrofuran (THF) at $40^{\circ} \mathrm{C}$ for 19 hours. The expected grafting mechanism is shown in Scheme 2. The resulting samples were then rinsed successively in pure THF and water.

Cyclic voltammetry experiments were carried out using a SP300 potentiostat (BioLogic, Claix, France) and a usual three-electrode electrochemical cell including (i) the working electrode described above, (ii) a platinum wire mesh of large area as counterelectrode and (iii) a silver wire as pseudo-reference electrode. An aqueous blank electrolytic solution containing perchloric acid (1 M) was used for the electrochemical characterisation of the grafted molecular layers [50].

\section{Results}

\subsection{Composition/thickness relations}

The intensity of the C1s and N1s photopeaks observed in the XPS survey spectra (see Figure 1) show that the nitrogen atomic content of the film increases with the nitrogen partial pressure in the plasma. The C1s and N1s high-resolution XPS spectra (not shown) allowed 
determining this dependence of the nitrogen atomic content as a function of the nitrogen partial pressure (see squares in Figure 2) [51-52]. In parallel, the film thickness was measured using FEG-SEM and plotted vs. nitrogen partial pressure in the gas mixture (see circles in Figure 2). It is worth noting that the a- $\mathrm{CN}_{\mathrm{x}}$ film thickness almost doubles from approximately $120 \mathrm{~nm}$ up to $200 \mathrm{~nm}$ as the nitrogen partial pressure is multiplied by ten from $3 \%$ up to 30 $\%$. Over this same range of nitrogen content, $\mathrm{x}$, the atomic nitrogen molar fraction in the a$\mathrm{CN}_{\mathrm{x}}$ layers increases from 0.12 up to 0.27 . This implies that the growth rate of these films increases with the nitrogen atomic content. Roughness of these a- $\mathrm{CN}_{\mathrm{x}}$ samples was also estimated from AFM images obtained with the contact mode of AFM (see Figure 3 for a representative image obtained on a- $\mathrm{CN}_{0.23}$ ). This latter was found to be $9 \pm 2.5 \AA$ depending on the nitrogen content in the a- $\mathrm{CN}_{\mathrm{x}}$ thin films. As a consequence, their real surface was found to be only $3 \%$ higher in average than their geometric area.

\subsection{Electroactivity of compound $\underline{4}$ in solution}

In a preliminary study, electroactivity of compound $\underline{4}$ in solution was investigated using cyclic voltammetry for different potential scan rates in a $1 \mathrm{M}$ perchloric acid aqueous solution, as this latter will be the blank solution used later on for the electrochemical characterisation of the electroactive layer resulting from grafting of compound $\underline{4}$ on a- $\mathrm{CN}_{\mathrm{x}}$ samples. It should be noticed here that solubility of $\underline{4}$ was found to be poor in such aqueous and acidic electrolytic solution in spite of the likely protonation of the $-\mathrm{CO}-\mathrm{NH}$ - functional group, giving to $\underline{4}$ a cationic charge. Resulting cyclic voltammograms shown in Figure 4a were obtained on a a-CN $\mathrm{CN}_{0,12}$ working electrode. Whatever the scan rate, the voltammograms show an anodic peak during the forward potential scan and a cathodic peak during the backward potential scan. These peaks can be attributed to the one electron reversible redox behaviour of the freely diffusing ferrocene moiety existing in compound $\underline{\mathbf{4}}$. This conclusion is 
further confirmed by the linear variation of the anodic and cathodic peak current densities with the square root of the potential scan rate (see Figure 4b) as expected from RandlesSevcik equation established for a fast electron transfer and linear semi-infinite diffusion [53].

In addition, $\Delta \mathrm{E}_{\mathrm{p}}$, the difference between the anodic and cathodic peak potentials (i.e. $\left.\mathrm{E}_{\mathrm{pa}}-\mathrm{E}_{\mathrm{pc}}\right)$, is $67 \pm 0.5 \mathrm{mV}$, which is close to the $58 \mathrm{mV}$ value expected for a fast one-electron transfer involving a freely diffusing redox-active species [53]. Moreover, $\Delta \mathrm{E}_{\mathrm{p}}$ was found to be mainly constant as a function of the potential scan rate, as expected for a reversible redox couple like the ferrocene/ferricinium redox couple. Moreover, CVs performed in the $\mathrm{HClO}_{4}$ (1 M) blank electrolytic solution in the absence of compound $\underline{4}$ (not shown) after transfer of the electrode used to produce CVs reported in Figure 4a did not show any redox peaks, thus confirming that no spontaneous and no specific grafting of compound $\underline{4}$ occurred in such experimental conditions.

\subsection{Electroactivity of compound $\underline{4}$ grafted on a-CN $\mathrm{N}_{\mathrm{x}}$ samples}

After immersion in a $0.01 \mathrm{M}$ solution of the redox probe $\underline{4}$ in THF for 19 hours at $40^{\circ} \mathrm{C}$, the a- $\mathrm{CN}_{\mathrm{x}}$ electrodes were removed and thoroughly rinsed using pure THF in a first step and then distilled water. They were then used as working electrodes in a $1 \mathrm{M}$ perchloric acid aqueous electrolytic solution without redox probe $\underline{4}$ so as to check whether the redox probe $\underline{4}$ had been actually grafted. The cyclic voltammograms shown in Figures 5a-d correspond to $\mathrm{a}-\mathrm{CN}_{\mathrm{x}}$ thin films for $\mathrm{x}=0.12,0.19,0.23$ and 0.27 respectively. These CVs all show two peaks, one anodic and one cathodic, that evidence the electrochemical response of redox probe $\underline{4}$ grafted on the a- $\mathrm{CN}_{\mathrm{x}}$ surface. These peaks are superimposed to background capacitive currents which depend on the atomic nitrogen fraction. This issue was discussed in ref [17] and can be explained partly by the varying charge carrier density in the a- $\mathrm{CN}_{\mathrm{x}}$ samples as function of the $\mathrm{x}$ value. In the subsequent treatments, Faradaic peak current 
densities and coulombic charge densities were extracted after subtraction of this background current. The anodic peak potential for the grafted molecule appears to be shifted by about 200 $\mathrm{mV}$ towards anodic potentials by comparison with that of the freely diffusing species, indicating possibly an orientation and/or a distance (resulting from the protonated form of the spacing arm) of the ferrocene moiety of the grafted molecule by comparison to the electrode surface that is less favourable for electron transfer. One should also notice from Figure 5 that $\Delta \mathrm{E}_{\mathrm{p}}$ never reaches zero whatever the tested a-CN $\mathrm{CN}_{\mathrm{x}}$ electrode and the potential scan rate. This fact is in contradiction with the theoretical prediction for cyclic voltammograms for an immobilised and fast redox couple monolayer. A graph showing the variation of $\Delta \mathrm{E}_{\mathrm{p}}$ as a function of the potential scan rate (v) is shown in Figure 6 between 50 and $200 \mathrm{mV} \cdot \mathrm{s}^{-1}$ for each of the four a- $\mathrm{CN}_{\mathrm{x}}$ films. Interestingly, for a- $\mathrm{CN}_{0.12}$, a- $\mathrm{CN}_{0.19}$, and a- $\mathrm{CN}_{0.23}, \Delta \mathrm{E}_{\mathrm{p}}$ reaches values lower, especially at lower scan rate values, than those measured on a- $\mathrm{CN}_{0.12}$ for the redox probe $\underline{4}$ diffusing freely in solution, most of which are below $58 \mathrm{mV}$, the lowest value one can expect from theory for a freely diffusing one-electron redox couple. In the case of a$\mathrm{CN}_{0.19}, \Delta \mathrm{E}_{\mathrm{p}}$ even reaches values as low as $18 \mathrm{mV}$ for very low scan rates, and anyway close to $40 \mathrm{mV}$ for some of the scan rate values (see open circles for a- $\mathrm{CN}_{0.19}$ in Figure 6). The $\Delta \mathrm{E}_{\mathrm{p}}$ values measured for the a- $\mathrm{CN}_{0.27}$ film are more doubtful at first glance as $\Delta \mathrm{E}_{\mathrm{p}}$ increases from $114 \mathrm{mV}$ up to $189 \mathrm{mV}$ in Figure 6 for an increase of the scan rate from 50 to $200 \mathrm{mV} . \mathrm{s}^{-1}$. In any case, as these voltammograms have all been obtained in a blank electrolytic solution, they can only show the redox activity of at most a molecular monolayer of covalently grafted redox probes. Let us notice here that well-known Laviron's treatment based on $\mathrm{E}_{\mathrm{pa}}-\log (\mathrm{v})$ and $\mathrm{E}_{\mathrm{pc}}-\log (\mathrm{v})$ plots [54] was not exploited here in view of the accurate determination of the apparent rate constant $\left(\mathrm{k}_{\mathrm{s}}\right)$ for electron transfer as a consequence of the narrow range of potential scan rates explored in Figure 5a-d. Indeed, this latter is not wide enough to show $\Delta \mathrm{E}_{\mathrm{p}}$ increase as a function of $\log (\mathrm{v})$ except maybe for the a- $\mathrm{CN}_{0.27}$ sample. Abovementioned 
Laviron's plots were nevertheless used in order to calculate a minimum value of $\mathrm{k}_{\mathrm{s}}$ for each of the four a- $\mathrm{CN}_{\mathrm{x}}$ samples. This latter was found to be $0.8 \mathrm{~s}^{-1}$ for a- $\mathrm{CN}_{0.27}$ and approximately $3 \mathrm{~s}^{-1}$ for a- $\mathrm{CN}_{0.12}, \mathrm{a}-\mathrm{CN}_{0.19}$ and a- $\mathrm{CN}_{0.23}$. These $\mathrm{k}_{\mathrm{s}}$ values are of the same order of magnitude than those published for other grafted ferrocene moieties [55-56].

XPS analysis confirmed the presence of ferrocene on the $\mathrm{a}-\mathrm{CN}_{\mathrm{x}}$ grafted surface. Indeed, the 'high-resolution' spectrum recorded in the Fe2p region shows two contributions $\mathrm{Fe} 2 \mathrm{p}_{3 / 2}$ and $\mathrm{Fe} 2 \mathrm{p}_{1 / 2}$ separated by $13.2 \mathrm{eV}$ [57] (Figure 7). In the same conditions the F1s contribution was not detected, ruling out non specific adsorption of compound $\underline{4}$.

The chemical grafting of $\underline{\mathbf{4}}$ on the a- $\mathrm{CN}_{\mathrm{x}}$ electrodes was further confirmed by plotting the variation of the anodic and cathodic peak current densities as a function of the potential scan rate for each of the four a-CN $\mathrm{x}_{\mathrm{x}}$ based working electrodes (see Figure 8). These current values were obtained after subtraction of the capacitive contribution measured from the interpolation of the baseline. The observed linear dependence for every a- $\mathrm{CN}_{\mathrm{x}}$ samples is in very good agreement with that predicted by theory of cyclic voltammetry for an immobilised electroactive molecular monolayer, according to equation (2) established for a fast electron transfer:

$$
j_{p a}=I_{p a} / A=\frac{n^{2} F^{2}}{4 R T} v \Gamma_{R}
$$

$F$ is the Faraday's constant $\left(96485 \mathrm{C} \cdot \mathrm{mol}^{-1}\right), R$, the ideal gas constant $\left(8.31 \mathrm{~J} \cdot \mathrm{mol}^{-1} \cdot \mathrm{K}^{-}\right.$ ${ }^{1}$ ), $T$, temperature (in $\mathrm{K}$ ). $\Gamma_{\mathrm{R}}$ is the superficial concentration of the grafted molecules (in mol.cm ${ }^{-2} . A$ is the working electrode area $\left(\right.$ in $\left.\mathrm{cm}^{2}\right), n$, the number of exchanged electrons $(1 \mathrm{in}$ the case of a ferrocene moiety).

According to this theory, the $J_{p a} / J_{p c} \mid$ ratio should be equal to 1 whatever the potential scan rate for all the a- $\mathrm{CN}_{\mathrm{x}}$ samples investigated in this work. This ratio actually varies between 0.7 and 1.3. Moreover, it is important to notice that this $J_{p a} /\left|J_{p c}\right|$ ratio and $\Delta \mathrm{E}_{\mathrm{p}}$ (see Figure 6) both differ from expected theoretical values (that are 1 (without unit) and $0 \mathrm{mV}$ 
respectively for reminder) as a function of the atomic nitrogen content in the a- $\mathrm{CN}_{\mathrm{x}}$ films. Nevertheless, the a-CN $\mathrm{CN}_{0.19}$ sample appears to display the $\Delta \mathrm{E}_{\mathrm{p}}$ values which are the closest to those expected from theory. Conversely, a- $\mathrm{CN}_{0.27}$ corresponding to the highest nitrogen content in the film displays for the same criteria the most remote values from theory. $J_{p a} / J_{p c} \mid$ and $\Delta \mathrm{E}_{\mathrm{p}}$ values for a- $\mathrm{CN}_{0.12}$ and a- $\mathrm{CN}_{0.23}$ samples show intermediate behaviours.

\section{Discussion}

Results reported above allow the calculation of $\Gamma_{4}$, the superficial concentration of covalently grafted redox probe $\underline{4} . \Gamma_{4}$ can be deduced from either equations (1) or (2):

$$
Q_{a}=n F A \Gamma_{4}
$$

In this equation, $Q_{a}$ is the anodic coulombic charge measured below the anodic peak in Figures 5a-d after subtraction of the contribution of the capacitive current. $A$ is the geometric area of the electrode according to the very smooth character of a-CN $\mathrm{CN}_{\mathrm{x}}$ samples (see Figure 3 and related comments). Equation (2) was preferred to equation (1) as a consequence of the various shapes observed for the anodic peaks in Figures 5a-d. The anodic charge was used rather than the cathodic charge so as to avoid any artefact resulting from a degradation of the grafted monolayer due for example to the oxidation of the ferrocene moiety in an aqueous solution [58]. $\Gamma_{4}$ values determined for each of the four a- $\mathrm{CN}_{\mathrm{x}}$ layers are reported in Table 1 , as well as the anodic charges used for the calculations. First of all, one has to evaluate the maximum possible value for $\Gamma_{4}$ assuming a surface saturation by grafted redox probes 4 . If one considers a spherical approximation for ferrocene heads corresponding to a projected molecular area of $34.2 \AA^{2}$ [59-60] and by assuming a perpendicular orientation for the grafted molecule, all ferrocene heads are located at the same distance from the substrate, imposed by the spacer arm. Therefore, $\Gamma_{4 \max }$ is deduced from the random loose packing configuration of disks of equal size (34.2 $\AA^{2}$ area) which represents about $77 \%$ of the projected electrode area 
[61]. This gives $\Gamma_{4 \max }=3.710^{-10} \mathrm{~mol} . \mathrm{cm}^{-2}$ or $2.210^{14}$ grafting sites $/ \mathrm{cm}^{2}$. This value must be compared to the total superficial concentration of nitrogen sites. Considering an average density $\rho\left(\mathrm{a}-\mathrm{CN}_{\mathrm{x}}\right)$ around $2 \mathrm{~g} \cdot \mathrm{cm}^{-3}$ [62 and references cited therein] for those materials, it comes a number of total atomic sites density of $2.010^{15} \mathrm{~cm}^{-2}$ (for a- $\mathrm{CN}_{0.12}$ ) from which one can calculate the total atomic nitrogen site density for the different samples (see Table 1) and then deduce the amine fraction from the $\Gamma_{4}$ values expressed in atomic sites.

It appears that these values are rather low, about $6.5 \%$ at the maximum, and by assuming that those amine sites obey an even and random distribution. These amine sites could partly result from the presence of residual hydrogen or coming from the dissociation of water as an impurity of the sputtering gas. However, it can be emphasized that the lower the atomic nitrogen content in the bulk of the film, the higher is the corresponding surface coverage and this is consistent with the increasing nitrile content observed by spectroscopic techniques when the atomic nitrogen content increases. (see Figure 9) [38-39].

Therefore, these results confirm that the covalent grafting of a redox probe has been successfully carried out on the surface of a-CN $\mathrm{CN}_{\mathrm{x}}$ thin films by using the specific formation of an amide type linkage between pre-existing surface amine groups, whether these latter are primary or secondary [46], and a fluorocarbonyl terminal group of the grafted redox probe. One should emphasise that, as imine-type functional groups are thought to be present on the surface of the a- $\mathrm{CN}_{\mathrm{x}}$ thin films $[13,43]$, one can not rule out their acylation and the subsequent covalent grafting of ferrocene based redox probes. It is nevertheless unlikely that these latter are involved in the electrochemical responses shown in Figure 5. It is indeed well established in literature that imines, whether they are substituted or not, are hydrolysed into aldehydes (or ketones) and amides in highly acidic aqueous solutions [63-64]. The overall hydrolysis mechanism of imines consists of an addition of water to the $\mathrm{C}=\mathrm{N}$ double-bond leading to an expulsion of the amide from a tetrahedral intermediate. Such hydrolysis reaction is likely to 
occur in the perchloric acid solution used during the electrochemical characterisation of the grafted redox probes.

Moreover, this successful covalent grafting of a redox probe on the a- $\mathrm{CN}_{\mathrm{x}}$ samples allowed us i) to confirm the spontaneous formation of surface amine groups on a- $\mathrm{CN}_{\mathrm{x}}$ films, ii) to estimate the amount of such functional groups, iii) to show that their amount is decreasing as the bulk atomic nitrogen content increases in these a- $\mathrm{CN}_{\mathrm{x}}$ materials and iv) to observe that the electrochemical reactivity of the grafted probes decreases with the nitrogen content in the film.

In addition, FEG-SEM observations of the profile of tested a-CN $\mathrm{CN}_{\mathrm{x}}$ thin films revealed a substantial increase of the growth rate as a function of the atomic nitrogen content detected in their bulk with the help of XPS measurements.

Although these conclusions are fundamental for some of the possible applications like biosensors of these innovative electrode materials, they are not sufficient to establish a better understanding of the surface distribution of the various hybridization types taking place between carbon and nitrogen in these films as a function of the bulk atomic nitrogen content. One can simply remind here that, whereas poor nitrogen contents are expected to produce higher amounts of $\mathrm{sp}^{3}$ and $\mathrm{sp}^{2}$ type hybridizations leading to more compact films at the atomic level, rich contents of nitrogen are likely to lead to bulkier and more amorphous structures resulting from $\mathrm{sp}^{1}$ type hybridizations (e.g. nitriles) [38-39,65]. In every case, taking into account the low and mean atomic nitrogen content in those a- $\mathrm{CN}_{\mathrm{x}}$ materials and keeping in mind that it is distributed over a wide variety of nitrogen based functional groups [7], the superficial concentrations of amine groups determined in our experimental conditions sound more than reasonable. However, the $\Gamma_{4}$ values reported in Table 1 may well be underestimated in the case where only a part of the surface amine groups react with the ferrocene derivative and/or if the amine groups are unevenly distributed. We nevertheless 
expect their variation as a function of the bulk atomic nitrogen content of a- $\mathrm{CN}_{\mathrm{x}}$ materials to reflect that of the reactive surface amine groups of these a- $\mathrm{CN}_{\mathrm{x}}$ materials.

Finally, it is also worthwhile to compare the efficiency of the "natural amination » described in this work by magnetron sputtering in the course of a- $\mathrm{CN}_{\mathrm{x}}$ elaboration, to the "purposely amination" done by different techniques after synthesis of BDD surfaces: either $\mathrm{N}_{2}[66,67]$ or $\mathrm{NH}_{3}[68,69]$ plasma treatments, $\mathrm{UV}$ treatments under $\mathrm{NH}_{3}$ atmosphere [70], or electrochemical treatments in liquid $\mathrm{NH}_{3}$ [71-72].

The most reliable $\mathrm{N}$ percentages and nitrogen functions identifications were obtained from XPS analysis. It must be emphasized that in all cases, the maximum amounts of superficial nitrogen and identified amine groups remain low, e.g. 6\% [67], $7.4 \%$ [69], 3\% [71], and in addition found to be evenly distributed on the surface [68]. The measured amounts by the electrochemical technique designed in this work yield thus low values but one can anticipate improved performances by tuning the deposition conditions, namely by adding ammonia to the sputtering gas at the end of the growth to increase amination of the surface. This is a way to answer the original question: further amination is necessary.

\section{Conclusions}

A strategy based on the covalent grafting of a redox probe has been successfully used to quantify surface amine groups thought to spontaneously form on a- $\mathrm{CN}_{\mathrm{x}}$ surfaces as a result of their surface chemical reactivity under ambient atmosphere. The selectivity of the grafting reaction is based on the formation of a $-\mathrm{CO}-\mathrm{NH}$ - type linkage between these surface amine terminations and fluorocarbonyl groups of the redox probes. The electrochemical behaviour of the grafted redox probes with a spacer arm, and that of the same probes diffusing freely in solution have been discriminated by cyclic voltammetry. A detailed analysis of the resulting voltammograms was necessary so as to analyze distortions observed on these CVs. By 
comparison with CVs expected from theory for an immobilised and reversible redox probe, these latter indeed revealed unexpected values for the $J_{p a}\left|J_{p c}\right|$ ratio and $\Delta \mathrm{E}_{\mathrm{p}}$ criteria that were moreover found to vary with the bulk atomic nitrogen content of the a- $\mathrm{CN}_{\mathrm{x}}$ films. These observations were shown to reflect the influence of this latter key-characteristic of a-CN $\mathrm{N}_{\mathrm{x}}$ thin films on their electrochemical reactivity.

Exploitation of the CV study also revealed that surface amine groups are generally little many, and moreover less and less numerous as the bulk atomic nitrogen content increases in a- $\mathrm{CN}_{\mathrm{x}}$ films. This trend is expected to apply at least to reactive surface amine groups as the overall amount of surface amine groups is possibly underestimated in these investigations. As a consequence, further investigations are currently underway to develop surface treatments allowing an increase of the number of surface amine groups on the surface of a-CN $\mathrm{CN}_{\mathrm{x}}$ materials.

In conclusion, beyond a better understanding of the surface chemistry of a- $\mathrm{CN}_{\mathrm{x}}$ materials, these observations clearly offer remarkable perspectives for the elaboration of smart surfaces via the use of adequate functionalisation strategies.

\section{Acknowledgements}

S. Borensztajn is warmly acknowledged for his expertise in FEG-SEM and Prof. J.- C. Moutet (Univ. J. Fourier, Grenoble, France) for helpful discussions regarding the synthesis of ferrocene moieties. S.I.C.T. and T.A. thank Brazilian agencies FAPESP (Proc. 09/53199-3), CNPq and INCT-Bioanalitica for financial support. S.I.C.T also acknowledges a special grant from Graduate Studies Provost (USP) for travelling. 


\section{References}

[1] R.L. McCreery, Advanced carbon electrode materials for molecular electrochemistry, Chemical Reviews 108 (2008) 2646.

[2] S. Ababou-Girard, H. Sabbah, B. Fabre, K. Zellama, F. Solal, C. Godet, Covalent grafting of organic layers on sputtered amorphous carbon: Surface preparation and coverage density, Journal of Physical Chemistry C 111 (2007) 3099.

[3] B. Sun, P.E. Colavita, H. Kim, M. Lockett, M.S. Marcus, L.M. Smith, R.J. Hamers, Covalent photochemical functionalization of amorphous carbon thin films for integrated realtime biosensing, Langmuir 22 (2006) 9598.

[4] S. Szunerits, R. Boukherroub, Different strategies for functionalization of diamond surfaces, Journal of Solid State Electrochemistry 12 (2008) 1205.

[5] A.Y. Liu, M.L. Cohen, Prediction of new low compressibility solids, Science, New Series, 245 (1989) 841.

[6] J. Robertson, C.A. Davis, Nitrogen doping of tetrahedral amorphous carbon, Diamond and Related Materials, 4 (1995) 441.

[7] A.C. Ferrari, S.E. Rodil, J. Robertson, Interpretation of infrared and Raman spectra of amorphous carbon nitrides, Physical Review B 67 (2003) 155306.

[8] K. Yoo, B. Miller, R. Kalish, X. Shi, X., Electrodes of nitrogen-incorporated tetrahedral amorphous carbon - A novel thin-film electrocatalytic material with diamond-like stability, Electrochemical and Solid-State Letters 2 (1999) 233.

[9] H. Cachet, C. Deslouis, M. Chouiki, B. Saidani, N.M.J. Conway, C. Godet, Electrochemistry of nitrogen-incorporated hydrogenated amorphous carbon films, Journal of the Electrochemical Society 149 (2002) E233.

[10] A. Zeng, E. Liu, S.N. Tan, S. Zhang, J. Gao, Cyclic voltammetry studies of sputtered nitrogen doped diamond-like carbon film electrodes, Electroanalysis 14 (2002) 1110. 
[11] Y.V. Pleskov, M.D. Krotova, V.I. Polyakov, A.V. Khomich, A.I. Rukovishnikov, B.L. Druz, I. Zaritskiy, Electrochemical behaviour of a-C : $\mathrm{N}: \mathrm{H}$ films, Journal of Electroanalytical Chemistry 519 (2002) 60.

[12] N.W. Khun, E. Liu, H.W. Guo, Cyclic voltammetric behavior of nitrogen-doped tetrahedral amorphous carbon films deposited by filtered cathodic vacuum arc, Electroanalysis 20 (2008) 1851.

[13] A. Lagrini, C. Deslouis, H. Cachet, M. Benlahsen, S. Charvet, Elaboration and electrochemical characterization of nitrogenated amorphous carbon films, Electrochemistry Communications 6 (2004) 245.

[14] A. Zeng, M.M.M. Bilek, D.R. McKenzie, P.A. Lay, Semiconductor properties and redox responses at a-C:N thin film electrochemical electrodes, Diamond and Related Materials 18 (2009) 1211.

[15] Y. Tanaka, M. Furuta, K. Kuriyama, R. Kuwabara, Y. Katsuki, T. Kondo, A. Fujishima, K. Honda, Electrochemical properties of N-doped hydrogenated amorphous carbon films fabricated by plasma-enhanced chemical vapor deposition methods, Electrochimica Acta 56 (2011) 1172.

[16] H. Cachet, C. Debiemme-Chouvy, C. Deslouis, A. Lagrini, V. Vivier, M. Benlahsen, S. Charvet, Improvement and characterization of the electrochemical reactivity of amorphous carbon nitride electrodes, Electrochemistry Communications 7 (2005) 496.

[17] P. Tamiasso-Martinhon, H. Cachet, C. Debiemme-Chouvy, C. Deslouis, Thin films of amorphous nitrogenated carbon a- $\mathrm{CN}_{\mathrm{x}}$ : Electron transfer and surface reactivity, Electrochimica Acta 53 (2008) 5752.

[18] F. Ghamouss, P.Y. Tessier, A. Djouadi, M.-P. Besland, M. Boujtita, Screen-printed carbon electrode modified on its surface with amorphous carbon nitride thin film: Electrochemical and morphological study, Electrochimica Acta 52 (2007) 5053. 
[19] A. Benchikh, C. Debiemme-Chouvy, H. Cachet, A. Pailleret, B. Saidani, L. Beaunier, M.H. Berger, C. Deslouis, Influence of electrochemical pre-treatment on highly reactive carbon nitride thin films deposited on stainless steel for electrochemical applications, Electrochimica Acta 75 (2012) 131.

[20] K. Yoo, B. Miller, X. Shi, R. Kalish, Copper electrodeposition and dissolution on tetrahedral amorphous carbon incorporating nitrogen, Journal of the Electrochemical Society 148 (2001) C95.

[21] N.W. Khun, E. Liu, Linear sweep anodic stripping voltammetry of heavy metals from nitrogen doped tetrahedral amorphous carbon thin films, Electrochimica Acta 54 (2009) 2890. [22] L.X. Liu, E. Liu, Nitrogenated diamond-like carbon films for metal tracing, Surface and Coatings Technology 198 (2005) 189.

[23] A. Zeng, E. Liu, S.N. Tan, S. Zhang, J. Gao, Stripping voltammetric analysis of heavy metals at nitrogen doped diamond-like carbon film electrodes, Electroanalysis 14 (2002) 1294.

[24] R.A. Medeiros, A. Benchikh, R.C. Rocha-Filho, O. Fatibello-Filho, B. Saidani, C. Debiemme-Chouvy, C. Deslouis, Simultaneous detection of ascorbic acid and dopamine with electrochemically pretreated carbon nitride electrodes: Comparison with boron-doped diamond electrodes, Electrochemistry Communications 24 (2012) 61.

[25] S.M. Lyth, Y. Nabae, S. Moriya, S. Kuroki, M.-A. Kakimoto, J.-I. Ozaki, S. Miyata, Carbon Nitride as a Nonprecious Catalyst for Electrochemical Oxygen Reduction, Journal of Physical Chemistry C 113 (2009) 20148.

[26] X. Wang, K. Maeda, A. Thomas, K. Takanabe, G. Xin, J.M. Carlsson, K. Domen, M. Antonietti, A metal-free polymeric photocatalyst for hydrogen production from water under visible light, Nature Materials 8 (2009) 76. 
[27] H.G. Kim, S.H. Ahn, J.G. Kim, S.J. Park, K.R. Lee, Corrosion performance of diamond-like carbon (DLC)-coated Ti alloy in the simulated body fluid environment, Diamond and Related Materials 14 (2005) 35.

[28] B. Tomcik, S.C. Seng, B. Balakrisnan, J.Y. Lee, Electrochemical tests on the carbon protective layer of a hard disk, Diamond and Related Materials 11 (2002) 1409.

[29] N.W. Khun, E. Liu, Effect of substrate temperature on corrosion performance of nitrogen doped amorphous carbon thin films in $\mathrm{NaCl}$ solution, Thin Solid Films 517 (2009) 4762.

[30] J.G. Lee, S.P. Lee, Humidity sensing properties of $\mathrm{CN}_{\mathrm{x}}$ film by RF magnetron sputtering system, Sensors and Actuators B 108 (2005) 450.

[31] F. Garrélie, N. Benchikh, C. Donnet, R.Y. Fillit, J.N. Rouzaud, J.Y. Laval, A. Pailleret, One-step deposition of diamond-like carbon films containing self-assembled metallic nanoparticles, by femtosecond pulsed laser ablation, Applied Physics A - Materials Science \& Processing 90 (2008) 211.

[32] M. Jain, Structure of iron-containing nitrogenated carbon, Journal of Physical Chemistry C 112 (2008) 9777.

[33] J.C. Byers, P. Tamiasso-Martinhon, C. Deslouis, A. Pailleret, O.A. Semenikhin, Atomic Force Microscopy Studies of Carbon Nitride $\left(\mathrm{CN}_{\mathrm{x}}\right)$ Films Deposited on a Conducting Polymer Substrate, Journal of Physical Chemistry C 114 (2010) 18474.

[34] J.C. Byers, F. Billon, C. Debiemme-Chouvy, C. Deslouis, A. Pailleret, O.A. Semenikhin, Photocurrent Generation in Carbon Nitride and Carbon Nitride/Conjugated Polymer Composites, ACS Applied Materials \& Interfaces 4 (2012) 4579.

[35] H. Cachet, C. Debiemme-Chouvy, C. Deslouis, A. Lagrini, V. Vivier, Correlation between electrochemical reactivity and surface chemistry of amorphous carbon nitride films Surface and Interface Analysis 38 (2006) 719. 
[36] W.T. Zeng, E. Broitman, N. Hellbren, K.Z. Xing, I. Ivanov, H. Sjöström, L. Hultman, J.-E. Sundgren, Reactive magnetron sputtering of $\mathrm{CN}_{\mathrm{x}}$ thin films at different substrate bias, Thin Solid Films 308-309 (1997) 223.

[37] S.E. Rodil, W.I. Milne, J. Robertson, L.M. Brown, Maximized sp(3) bonding in carbon nitride phases, Applied Physics Letters 77 (2000) 1458.

[38] S.S. Roy, R. McCann, P. Papakonstantinou, P. Maguire, J.A. McLaughlin, The structure of amorphous carbon nitride films using a combined study of NEXAFS, XPS and Raman spectroscopies, Thin Solid Films 482 (2005) 145.

[39] A. Majumdar, J. Schäfer, P. Mishra, D. Ghose, J. Meichsner, R. Hippler, Chemical composition and bond structure of carbon-nitride films deposited by $\mathrm{CH}_{4} / \mathrm{N}_{2}$ dielectric barrier discharge, Surface and Coatings Technology 201 (2007) 6437.

[40] M. Aono, S. Aizawa, N. Kitazawa, Y. Watanabe, XPS study of carbon nitride films deposited by hot filament chemical vapor deposition using carbon filament, Thin Solid Films $516(2008) 648$.

[41] A. Majumdar, G. Scholz, R. Hippler, Structural characterization of amorphous hydrogenated-carbon nitride (aH-CN) film deposited by $\mathrm{CH}_{4} / \mathrm{N}_{2}$ dielectric barrier discharge plasma: C-13, H-1 solid state NMR, FTIR and elemental analysis, Surface and Coatings Technology 203 (2009) 2013.

[42] K.-M. Roh, S.-J. You, S.K. Choi, J.-H. Kim, D.-J. Seong, Influence of $\mathrm{N}_{2}$ gas pressure on the chemical bonds of amorphous carbon nitride films, Journal of Physics D: Applied Physics 42 (2009) 1.

[43] A. Lagrini, S. Charvet, M. Benlahsen, H. Cachet, C. Deslouis, On the relation between microstructure and electrochemical reactivity of sputtered amorphous carbon nitride electrodes, Diamond and Related Materials 16 (2007) 1378. 
[44] A. Bousetta, M. Lu, A. Bensaoula, A. Schultz, Formation of carbon nitride films on Si(100) substrates by electron-cyclotron-resonance plasma-assisted vapor deposition, Applied Physics Letters 65 (1994) 696.

[45] O. Durand-Drouhin, M. Benlahsen, Internal stress of sputtered amorphous carbon nitride thin films, Solid State Communications 131 (2004) 425.

[46] Yi-Chun Liu and Richard L. McCreery, Reactions of Organic Monolayers on Carbon Surfaces Observed with Unenhanced Raman Spectroscopy, J. Am. Chem. Soc., 117 (1995) 11254.

[47] S. Sam, L. Touahir, J. Salvador Andresa, P. Allongue, J.-N. Chazalviel, A. C. GougetLaemmel, C. Henry de Villeneuve, A. Moraillon, F. Ozanam, N. Gabouze, S. Djebbar, Semiquantitative Study of the EDC/NHS Activation of Acid Terminal Groups at Modified Porous Silicon Surfaces, Langmuir 2010, 26(2), 809-814.

[48] T.H. Galow, J. Rodrigo, K. Cleary, G. Cooke, V.M. Rotello, Fluorocarbonylferrocene. A versatile intermediate for ferrocene esters and amides, Journal of Organic Chemistry 64 (1999) 3745.

[49] R. Villoslada, B. Alonso, C.M. Casado, P. García-Armada, J. Losada, Anion Receptor Electrochemical Sensing Properties of Poly(propyleneimine) Dendrimers with Ferrocenylamidoalkyl Terminal Groups, Organometallics 28 (2009) 727.

[50] E.C. Landis, R.J. Hamers, Covalent Grafting of Ferrocene to Vertically Aligned Carbon Nanofibers: Electron-transfer Processes at Nanostructured Electrodes, Journal of Physical Chemistry C 112 (2008) 16910.

[51] A. Lagrini, S. Charvet, M. Benlahsen, C. Debiemme-Chouvy, C. Deslouis, H. Cachet, Microstructure and electronic investigations of carbon nitride films deposited by RF magnetron sputtering, Thin Solid Films 482 (2005) 41. 
[52] F. Alibart, O. Durand-Drouhin, C. Debiemme-Chouvy, M. Benlahsen, Relationship between the structure and the optical and electrical properties of reactively sputtered carbon nitride films, Solid State Communications 145 (2008) 392.

[53] A.J. Bard, L.R. Faulkner, Electrochemistry, principles, methods and applications, Eds Masson, New-York, U.S.A., 1983.

[54] E. Laviron, General expression of the linear potential sweep voltammogram in the case of diffusionless electrochemical systems, Journal of Electroanalytical Chemistry 101 (1979) 19.

[55] B. Fabre, F. Hauquier, Single-component and mixed ferrocene-terminated alkyl monolayers covalently bound to Si(111) surfaces, Journal of Physical Chemistry B 110 (2006) 6848.

[56] J. Ghilane, J.C. Lacroix, Formation of a bifunctional redox system using electrochemical reduction of platinum in ferrocene based ionic liquid and its reactivity with aryldiazonium, Journal of the American Chemical Society, 135 (2013) 4722.

[57] B. Fischer, M.S. Wrighton, M. Umana, R.W. Murray, X-Ray photoelectron spectroscopic study of multilayers of an electroactive ferrocene derivative attached to platinum and gold electrodes, Journal of the American Chemical Society 101 (1979) 3442.

[58] G. Riveros, G. González, B. Chornik, Electron transfer rates of alkyl-ferrocene molecules forming incomplete monolayer on silicon electrodes, Journal of the Brazilian Chemical Society 21 (2010) 25.

[59] T. Kondo, H. Hoshi, K. Honda, Y. Einaga, A. Fujishima, T. Kawai, Photochemical modification of a boron-doped diamond electrode surface with vinylferrocene, Journal of Physical Chemistry C 112 (2008) 11887. 
[60] C.E.D. Chidsey, C.R. Bertozzi, T.M. Putvinski, A.M. Mujsce, Coadsorption of ferrocene-terminated and unsubstituted alkanethiols on gold-electroactive self-assembled monolayers, Journal of the American Chemical Society 112 (1990) 4301.

[61] E.L. Hinrichsen, J. Feder, T. Jøssang, Random packing of disks in two dimensions, Phys. Rev. A 41 (1990) 4199.

[62] W. Kulisch, M.P. Delplancke-Ogletree, J. Bulir, M. Jelinek, K. Jurek, J. Zemek, J. Klimovic, Characterization of magnetron sputtered carbon nitride films, Diamond and Related Materials, 8 (1999) 1039.

[63] J. Hine, J.C. Craig, J.G. Underwood II, F.A. Via, Kinetics and mechanism of hydrolysis of $\mathrm{N}$-isobutylidenemethylamine in aqueous solution, Journal of the American Chemical Society 92 (1970) 5194.

[64] E.H. Cordes, W.P. Jencks, Mechanism of hydrolysis of Schiff bases derived from aliphatic amines, Journal of the American Chemical Society 85 (1963) 2843.

[65] N.E. Derradji, M.L. Mahdjoubi, H. Belkhir, N. Mumumbila, B. Angleraud, P.Y. Tessier, Nitrogen effect on the electrical properties of $\mathrm{CNx}$ thin films deposited by reactive magnetron sputtering, Thin Solid Films 482 (2005) 258.

[66] S.F. Durrant, V. Baranauskas, A. Peterlevitz, B.B. Li, M.C. Tosin, E.C. Rangel, J. Wang, S.G. Castro, M.A.B. de Moraes, Nitrogenation of diamond by glow discharge plasma treatment. Thin Solid Films 355 (1999) 184.

[67] A. Denisenko, A. Romanyuk, L.A. Kibler, E. Kohn, Surface structure and electrochemical characteristics of boron-doped diamond exposed to rf $\mathrm{N}_{2}$-plamsa. Journal of Electroanalytical Chemistry 657 (2011) 164.

[68] S. Szunerits, C. Jama, Y. Coffinier, B. Marcus, D. Delabouglise, R. Boukherroub, Direct amination of hydrogen-terminated boron doped diamond surfaces. Electrochemistry Communications 8 (2006) 1185. 
[69] H. Koch, W. Kulisch, C. Popov, R. Merz, J.P. Reithmaier, Plasma amination of ultrananocrystalline diamond/amorphous carbon composite films for the attachment of biomolecules. Diamond and Related Materials 20 (2010) 254.

[70] S. Torrengo, A. Miotello, L. Minati, I. Bernagozzi, M. Ferrari, M. Dipalo, E. Kohn, G. Speranza, The role of oxygen in the one step amination process of nanocrystalline diamond surface. Diamond and Related Materials 20 (2011) 990.

[71] N. Simon, C. Decorse-Pascanut, A.M. Goncalves, D. Ballutaud, G. Charrier, A. Etcheberry, Nitrogenation of boron doped diamond: Comparison of an electrochemical treatment in liquid ammonia and a $\mathrm{NH}(3) / \mathrm{N}(2)$ plasma. Diamond and Related Materials 18 (2009) 890 .

[72] F.J. Del Campo, C. H. Goeting, D. Morris, J.S. Foord, A. Neudeck, R.G. Compton, F. Marken, Voltammetry at boron-doped diamond electrodes in liquid ammonia: Solvent window effects and diamond surface modification. Electrochemical and Solid State Letters 3 (2000) 224 . 
Scheme 1: synthetic route used for the synthesis of grafted molecules $\underline{\mathbf{2}}$ and $\underline{\mathbf{4}}$.

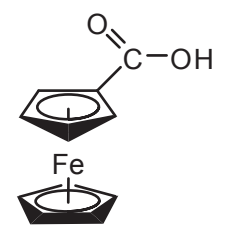

1

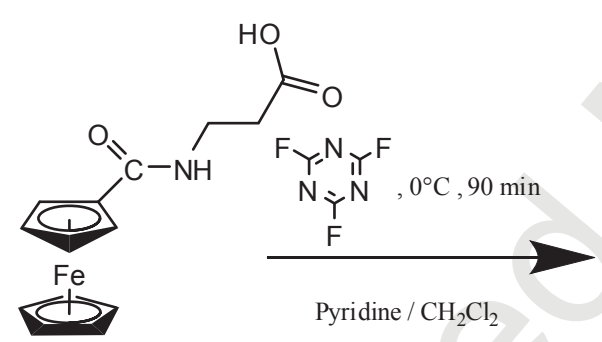

$\underline{3}$

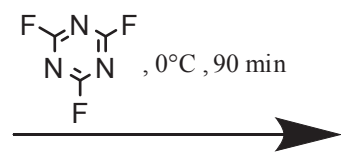

Pyridine $/ \mathrm{CH}_{2} \mathrm{Cl}_{2}$

Pyridine $/ \mathrm{CH}_{2} \mathrm{Cl}_{2}$

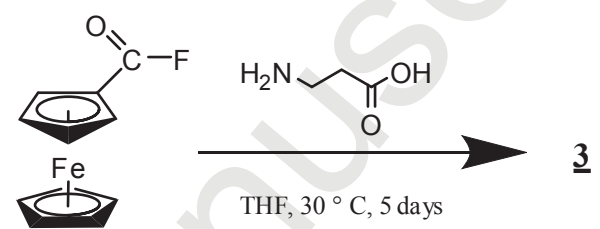

$\underline{2}$

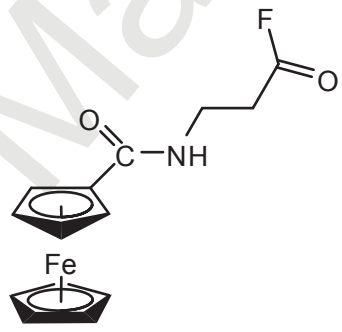

4 
Scheme 2: grafting route for redox probe $\underline{4}$ on surface amine groups of $\mathrm{CN}_{\mathrm{x}}$ materials. The grey rectangles represent a- $\mathrm{CN}_{\mathrm{x}}$ thin film.
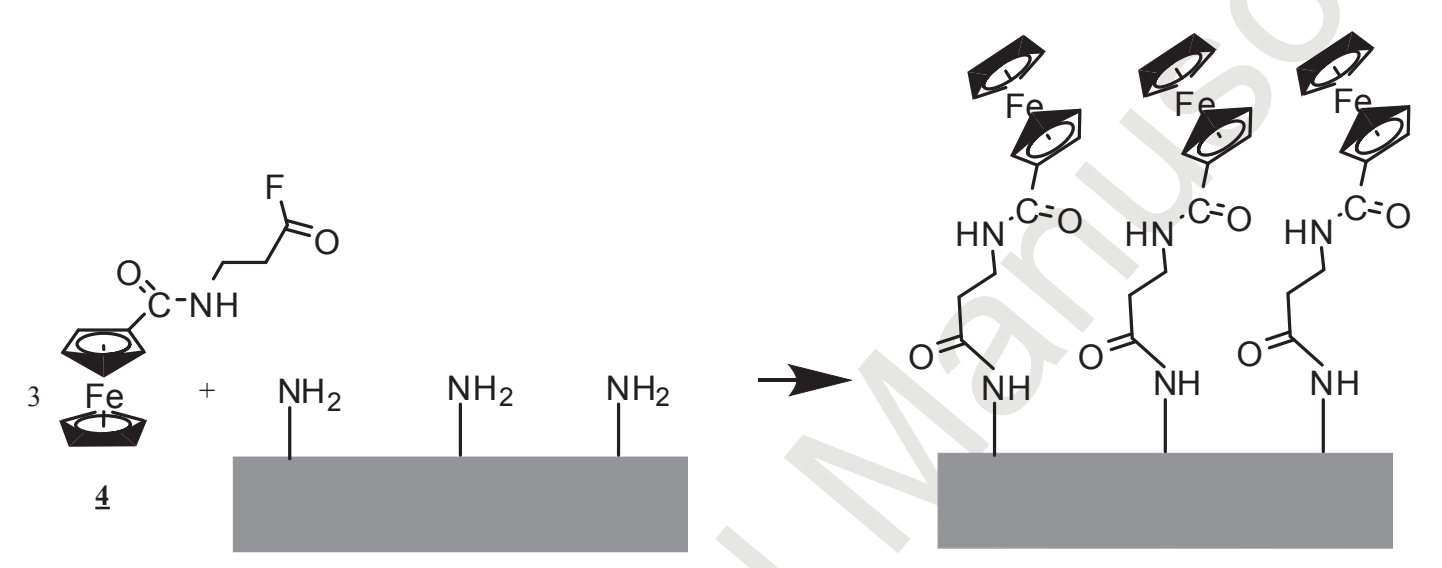


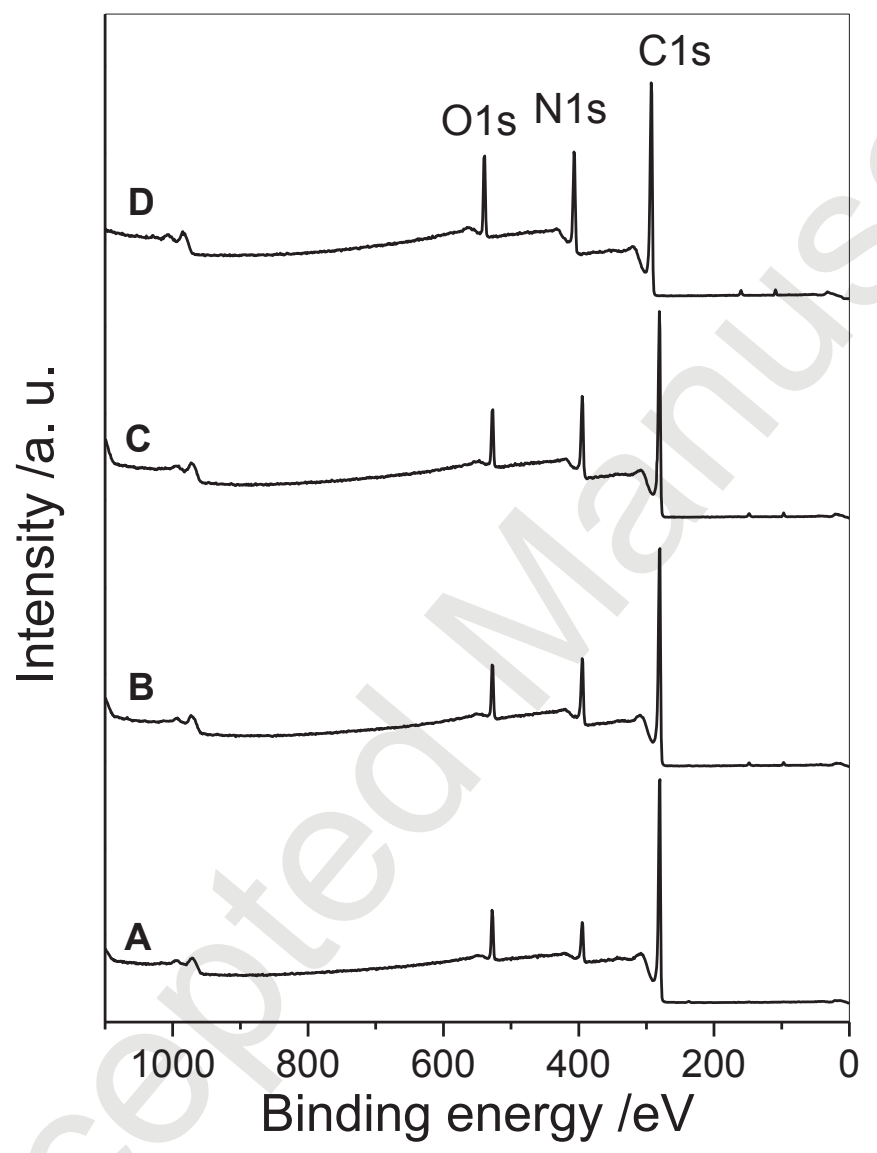

Figure 1 : Survey XPS spectra from a-CN ${ }_{x}$ samples. x: 0.12 (A), 0.19 (B), 0.23 (C), 0.27 (D). 


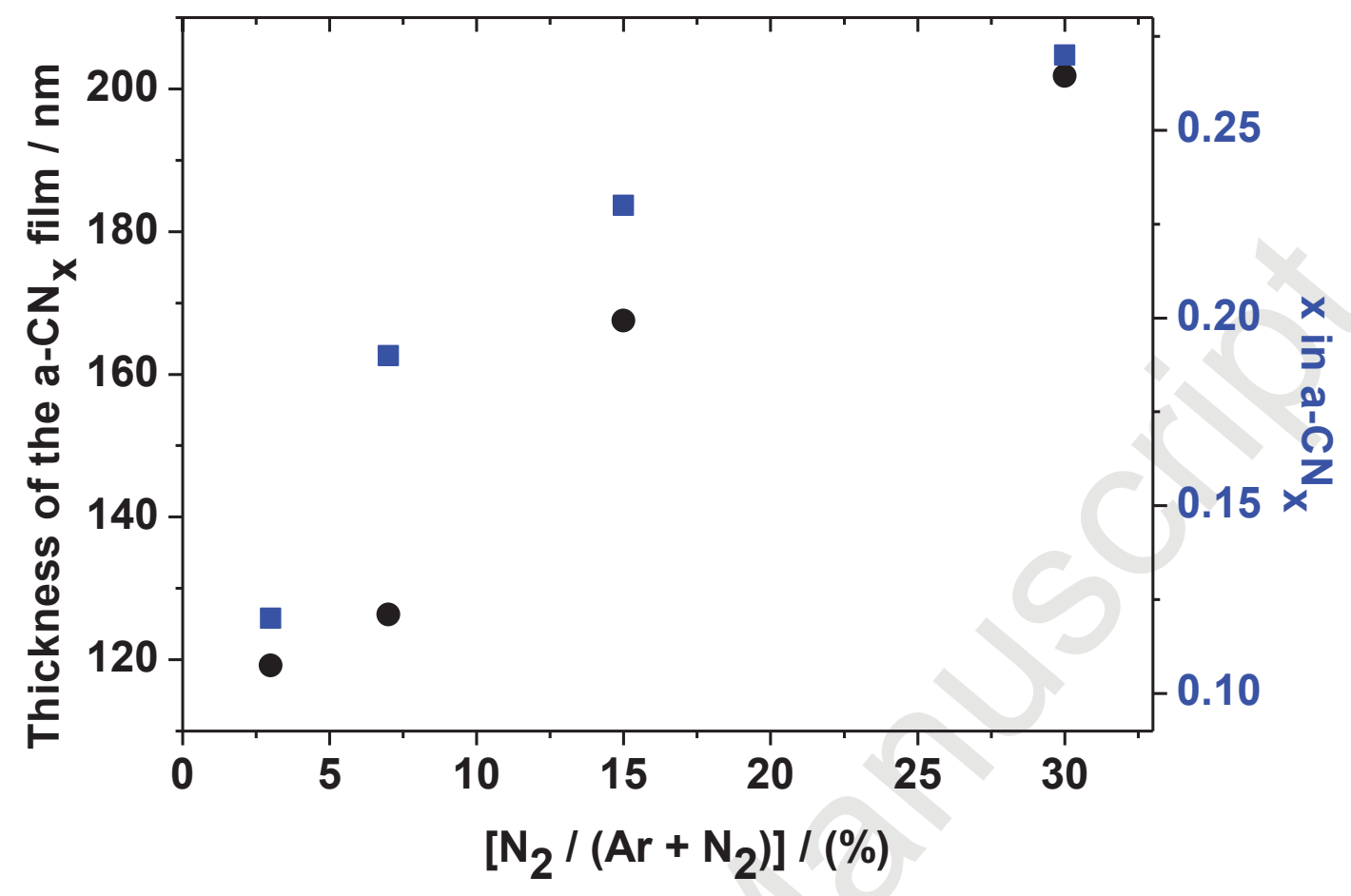

Figure 2: Atomic nitrogen fraction ( $\square$ ) and thickness $(\bullet)$ of a-CN $\mathrm{CN}_{\mathrm{x}}$ thin films as a function of the gaseous nitrogen content, expressed in percentage, in the gas mixture used during the elaboration process. Deposition time: 10 minutes. 

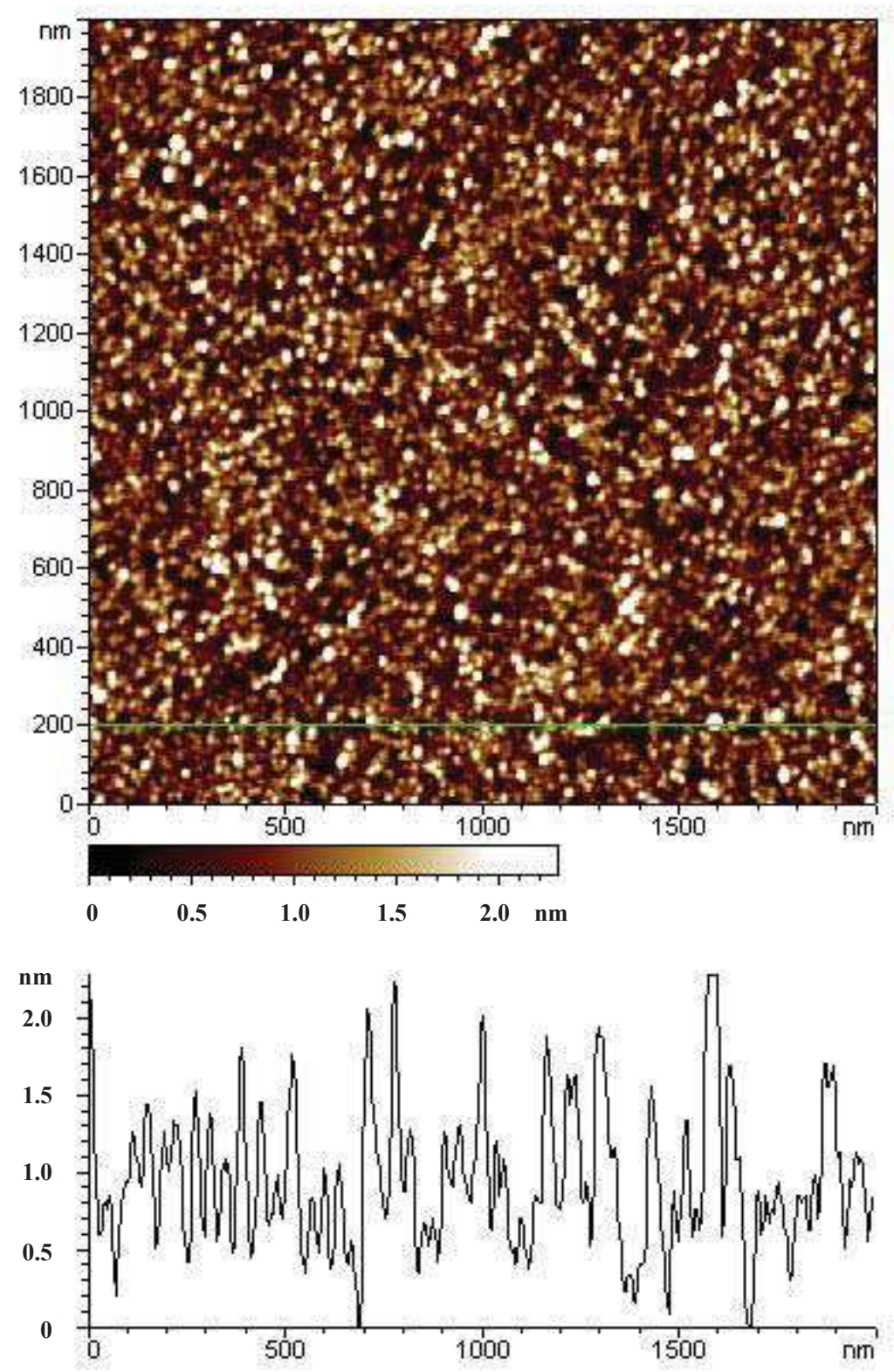

Figure 3 : AFM image obtained in the contact mode on a a- $\mathrm{CN}_{0.23}$ sample deposited on a pdoped silicon substrate according to part 1 of the experimental part. A profile taken along the green line appearing on this image is shown below it. RMS roughness value calculated over the full area of this $2 \times 2 \mu \mathrm{m}$ AFM image by using the Picoscan software was found to be 0.9 nm. 

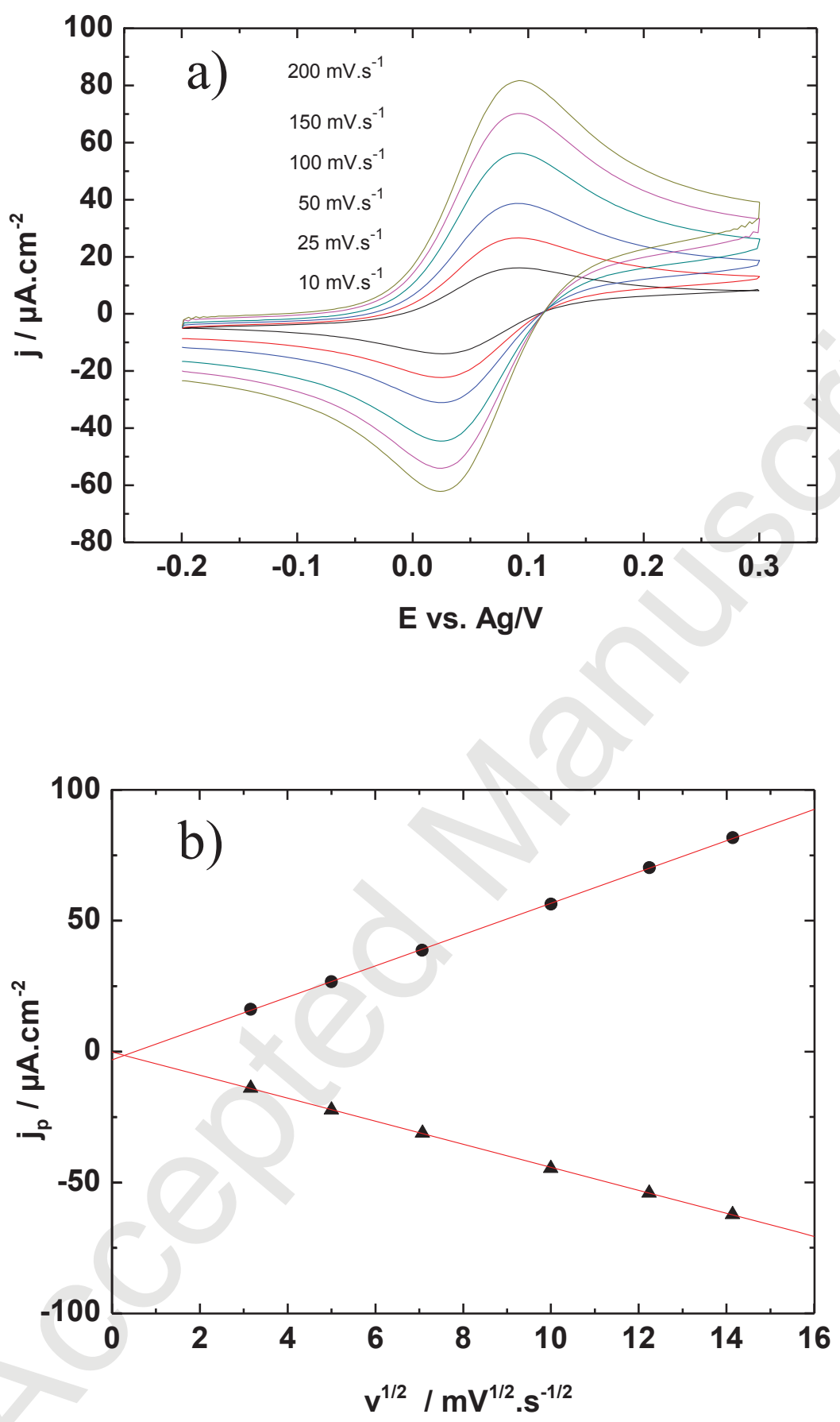

Figure 4: a) Cyclic voltammograms showing the electroactivity of the freely diffusing redox probe $\underline{4}$ for different scan rates on an a- $\mathrm{CN}_{0.12}$ electrode in a $1 \mathrm{M}$ perchloric acid aqueous solution. Ref.: silver wire. CE: Pt. b) Variation of anodic $(\bullet)$ and cathodic $(\boldsymbol{\Delta})$ peak current densities as a function of the square root of the scan rate. 

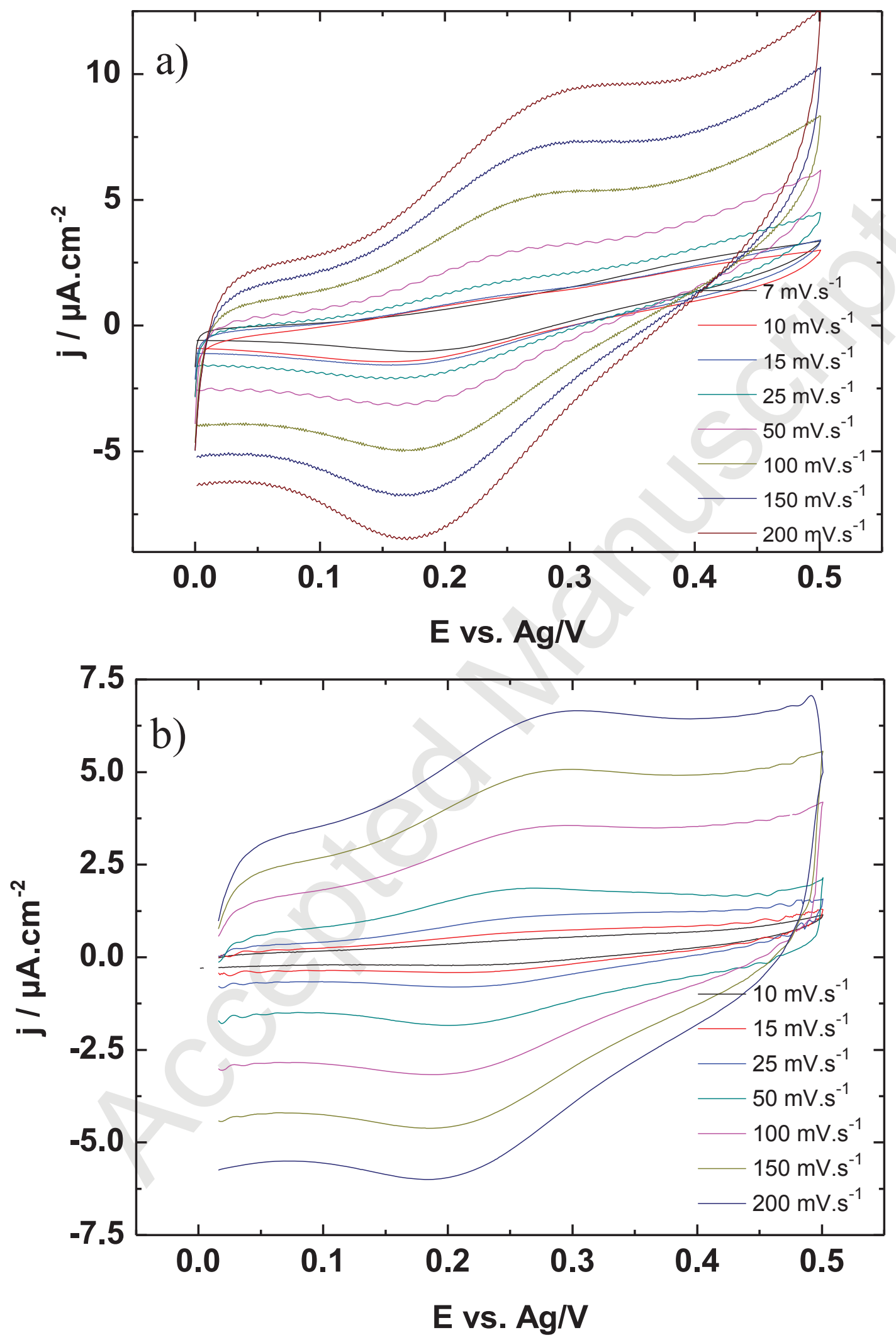

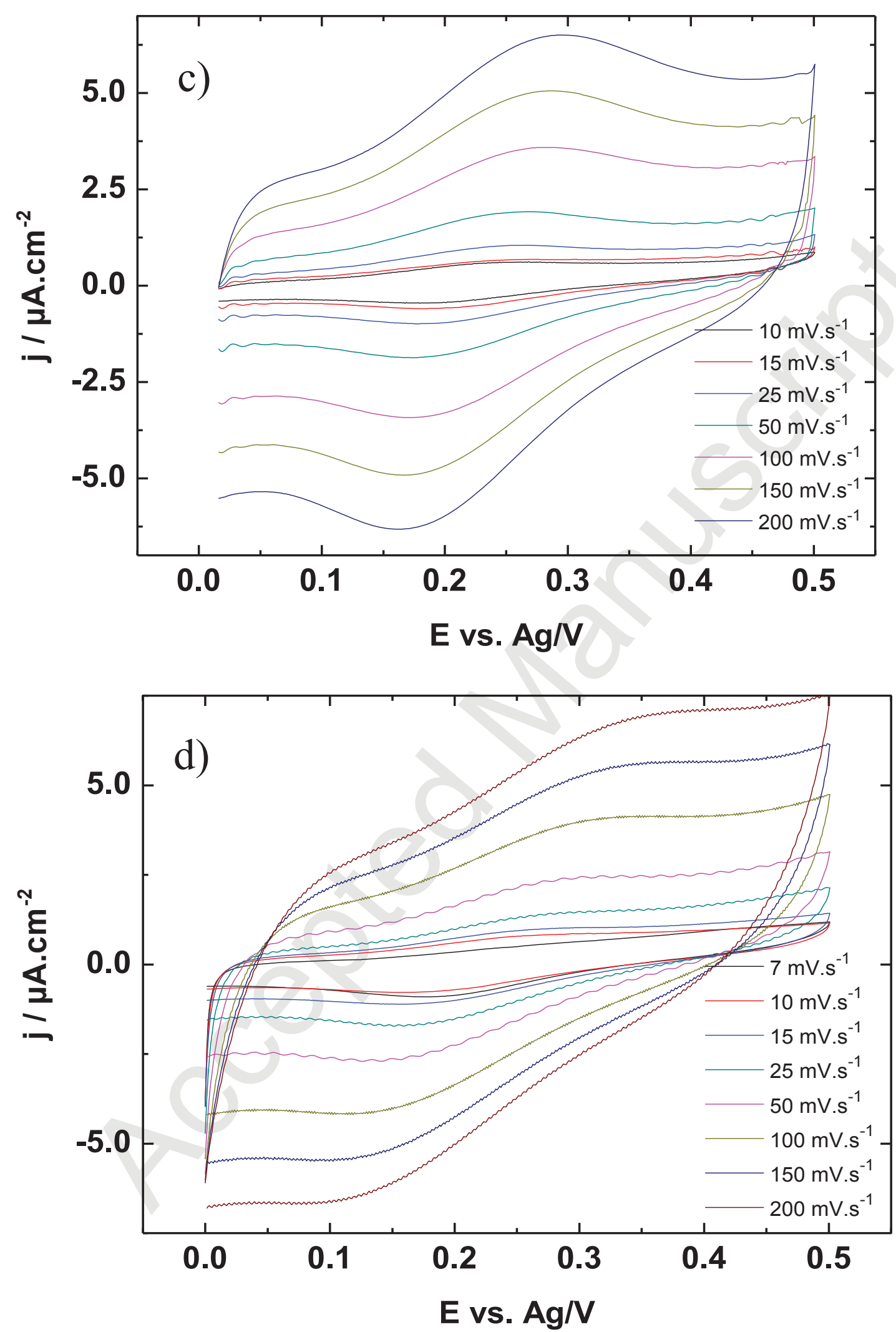

Figure 5: Cyclic voltammograms showing the electrochemical behaviour of the electroactive layer resulting from the covalent grafting of $\underline{4}$ for different scan rates on 4 different a- $\mathrm{CN}_{\mathrm{x}}$ samples for which $x=a) 0.12$, b) 0.19 , c) 0.23 d) 0.27 . Ref.: silver wire. CE: Pt. 


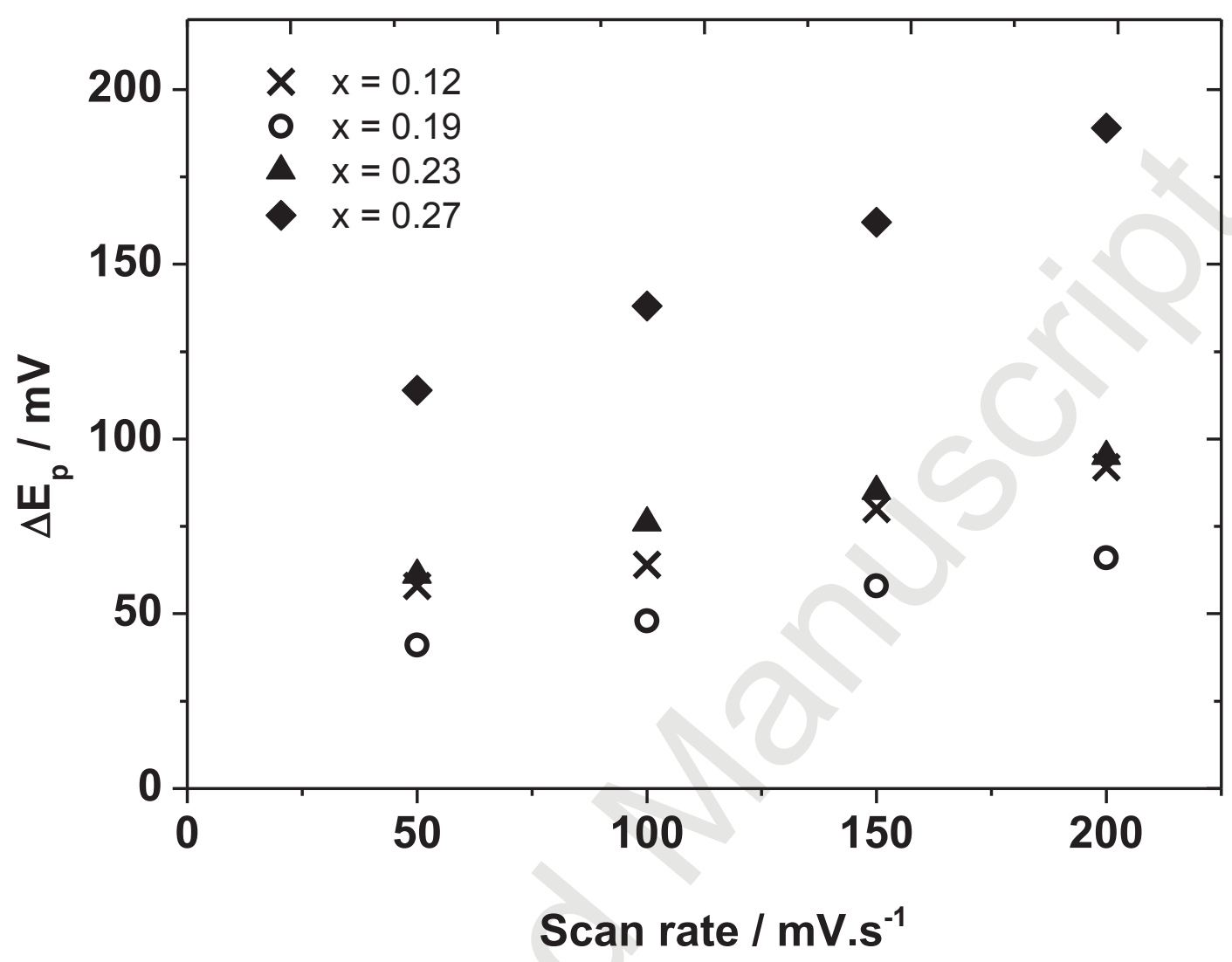

Figure 6: Peak potential difference (extracted from Figure 5) related to the electroactive layer resulting from the covalent grafting of $\underline{\mathbf{4}}$, as a function of the scan rate for 4 different a- $\mathrm{CN}_{\mathrm{x}}$ films. 


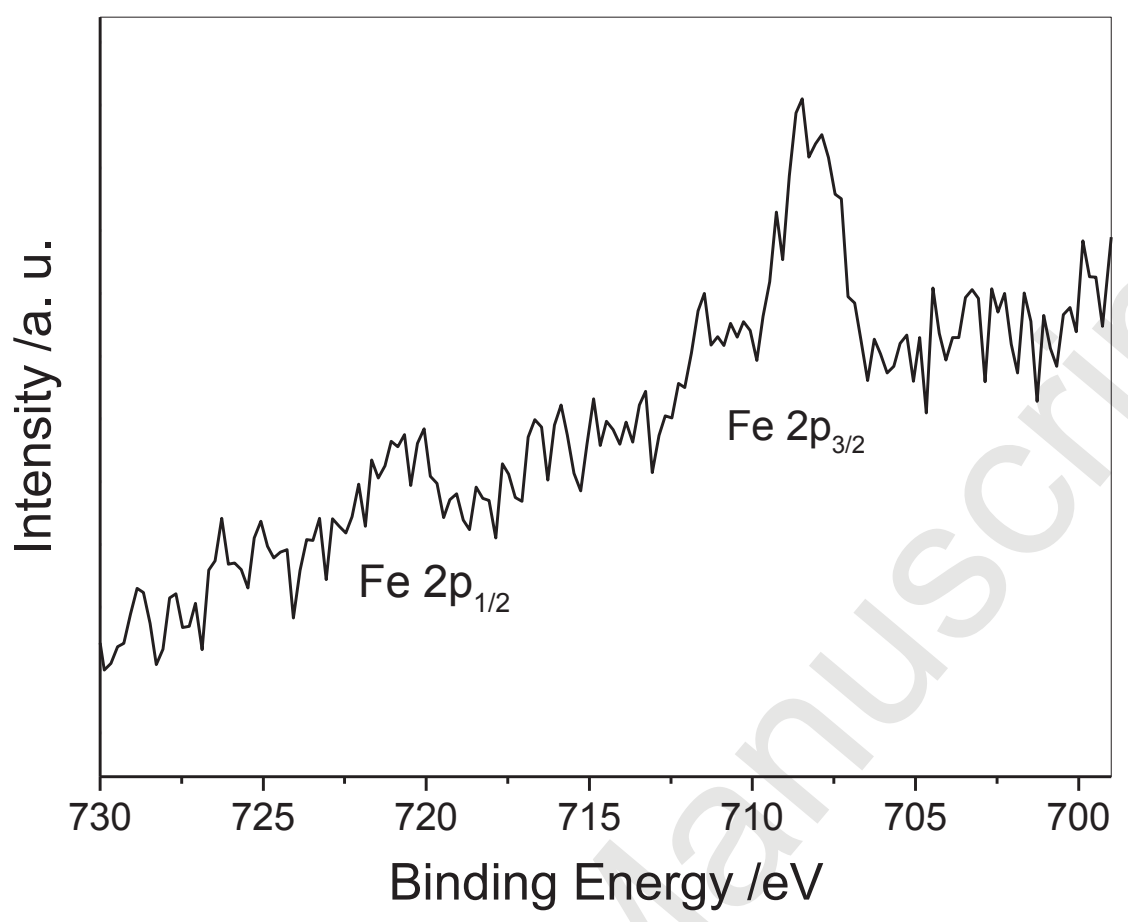




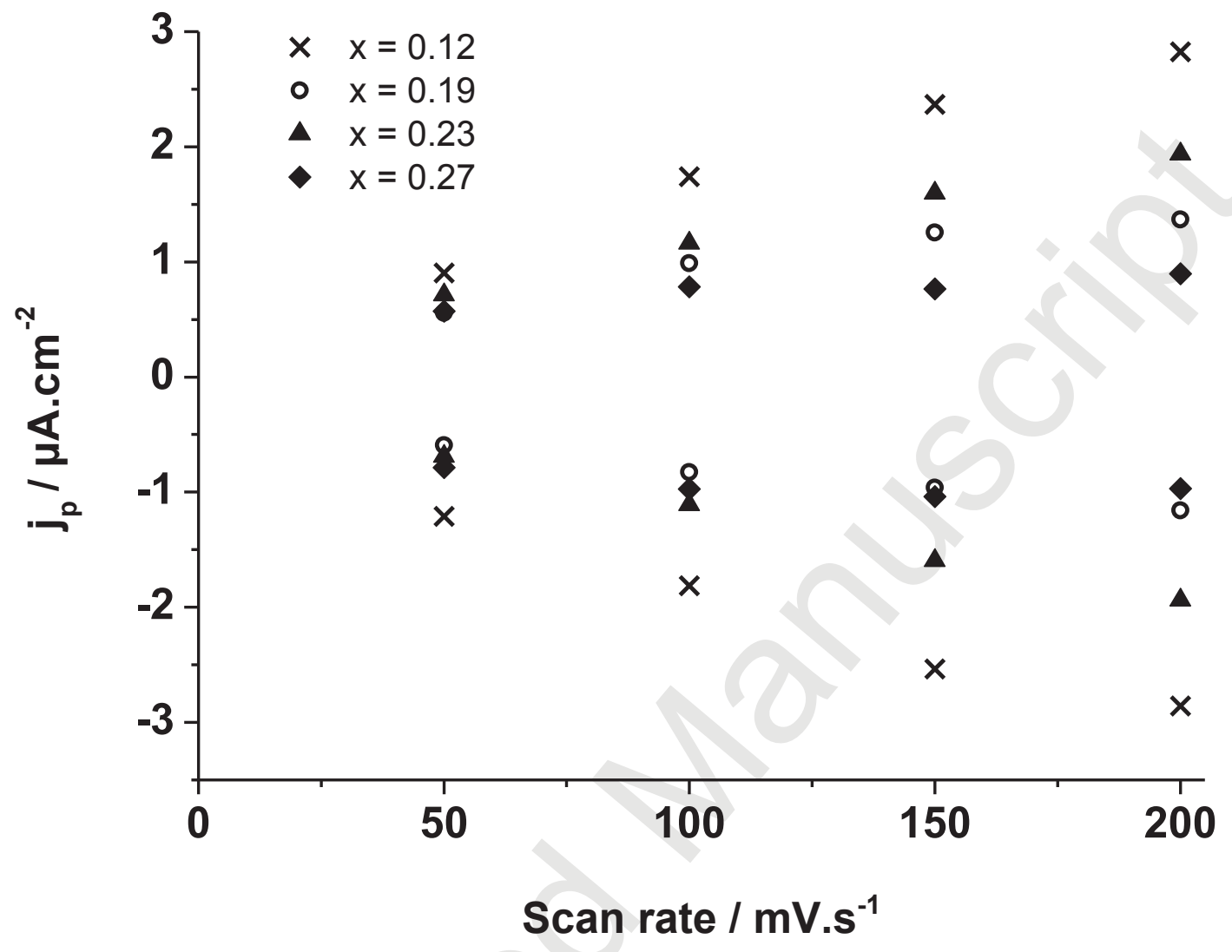

Figure 8: Variation of the anodic and cathodic peak current densities (extracted from Figure 5 ) related to the electro-active layer resulting from the covalent grafting of $\underline{\mathbf{4}}$, as a function of the scan rate for 4 different a- $\mathrm{CN}_{\mathrm{x}}$ films. 


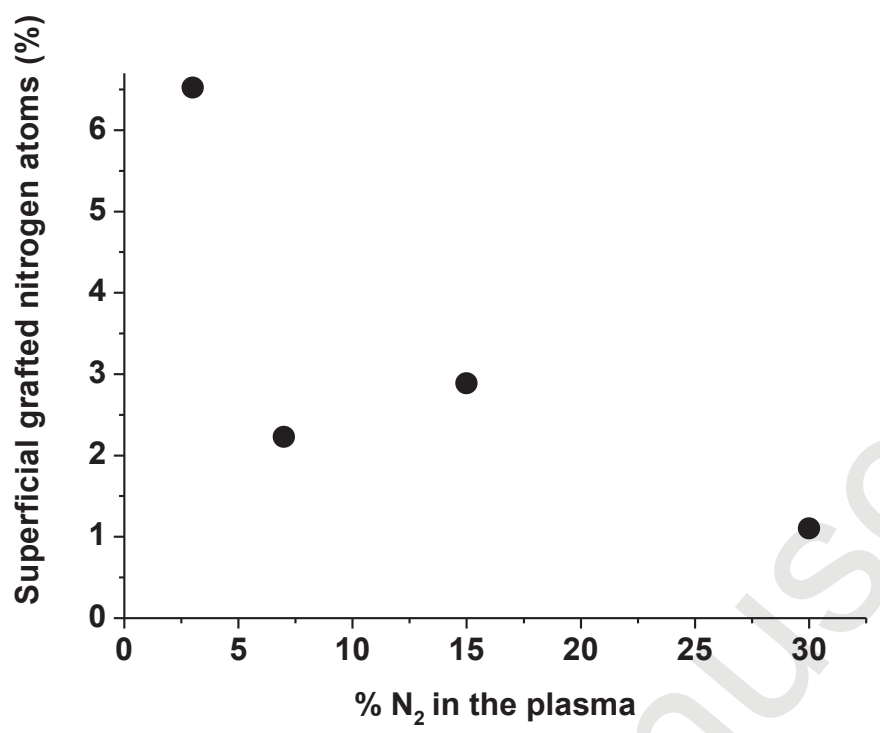

Figure 9: Percentage of superficial grafted nitrogen atoms for different $\mathrm{N}_{2}$ gas content in the plasma used during the deposition process of a- $\mathrm{CN}_{\mathrm{x}}$ films. 
Table 1 : Total number of grafted amine sites, and of $\mathrm{N}$ sites, per $\mathrm{cm}^{2}$, and percentage of superficial grafted nitrogen atoms as a function of $\mathrm{x}$, bulk nitrogen content expressed for one carbon atom.

\begin{tabular}{|c|c|c|c|c|c|c|c|}
\hline $\begin{array}{c}x \\
\text { (in } \mathrm{a}-\mathrm{CN}_{\mathrm{x}} \text { ) }\end{array}$ & $\begin{array}{c}\mathrm{Q}_{\mathrm{a}} / \\
\underset{\text { (1) }}{(1)}\end{array}$ & $\mathrm{S} / \mathrm{cm}_{(2)}^{2}$ & $10^{11} \underset{(3)}{\Gamma_{4} /}$ & $\begin{array}{c}\mathrm{N}_{\mathrm{at}} / \\
10^{12} \mathrm{~cm}^{-2} \\
\text { grafted } \\
\text { amine sites } \\
(4)\end{array}$ & $\mathrm{N}_{\mathrm{at}} /\left(\mathrm{C}_{(5)}+\mathrm{N}_{\mathrm{at}}\right)$ & $\begin{array}{l}\mathrm{N}_{\mathrm{at}} / 10^{14} \mathrm{~cm}^{-2} \\
\text { Total } \underset{(6)}{\mathrm{N}} \text { sites }\end{array}$ & $\begin{array}{c}\text { Grafted } \\
\text { nitrogen } \\
\% \\
\text { (7) }\end{array}$ \\
\hline 0.12 & 2.22 & 0.54 & 2.3 & 14 & 0.107 & 2.1 & 6.5 \\
\hline 0.19 & 1.08 & 0.49 & 1.1 & 6.7 & 0.160 & 3.0 & 2.2 \\
\hline 0.23 & 1.59 & 0.64 & 1.6 & 9.9 & 0.187 & 3.4 & 2.9 \\
\hline 0.27 & 0.68 & 0.90 & 0.70 & 4.2 & 0.213 & 3.8 & 1.1 \\
\hline
\end{tabular}

(1) anodic charge density measured below the anodic peak in CVs shown in Fig. 5 for a $200 \mathrm{mV} . \mathrm{s}^{-1}$ scan rate, (2) measured with the help of picture analysis procedure, (3) $\Gamma_{4}=\mathrm{Q}_{\mathrm{a}} / \mathrm{F}$, (4) $\mathrm{N}_{\mathrm{at}}=\mathrm{N}_{\mathrm{A}} \times \Gamma_{4}$ (with $\mathrm{N}_{\mathrm{A}}=$ Avogadro's number), (5) calculated by using the expression $\mathrm{x} /(1+\mathrm{x}$ ), (6) calculated from the total atomic site density (calculated from $\left(\rho\left(a-C N_{x}\right) N_{A} / M\left(a-C N_{x}\right)\right)^{2 / 3}$ avec $\left.M\left(a-C N_{x}\right)=12+14 x\right)$ multiplied by (5), (7) calculated from the ratio (4) over (6). 